NASA/CR-2002-211344

ARL-CR-486
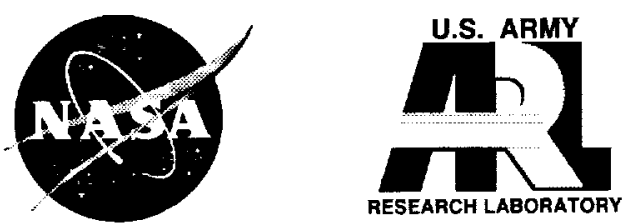

Design and Stress Analysis of Low-Noise Adjusted Bearing Contact Spiral Bevel Gears

Faydor L. Litvin and Alfonso Fuentes

University of Illinois at Chicago, Chicago, Illinois

Baxter R. Mullins and Ron Woods

Bell Helicopter Textron, Inc., Fort Worth, Texas 
Since its founding, NASA has been dedicated to the advancement of aeronautics and space science. The NASA Scientific and Technical Information (STI) Program Office plays a key part in helping NASA maintain this important role.

The NASA STI Program Office is operated by Langley Research Center, the Lead Center for NASA's scientific and technical information. The NASA STI Program Office provides access to the NASA STI Database, the largest collection of aeronautical and space science STI in the world. The Program Office is also NASA's institutional mechanism for disseminating the results of its research and development activities. These results are published by NASA in the NASA STI Report Series, which includes the following report types:

- TECHNICAL PUBLICATION. Reports of completed research or a major significant phase of research that present the results of NASA programs and include extensive data or theoretical analysis. Includes compilations of significant scientific and technical data and information deemed to be of continuing reference value. NASA's counterpart of peerreviewed formal professional papers but has less stringent limitations on manuscript length and extent of graphic presentations.

- TECHNICAL MEMORANDUM. Scientific and technical findings that are preliminary or of specialized interest, e.g., quick release reports, working papers, and bibliographies that contain minimal annotation. Does not contain extensive analysis.

- CONTRACTOR REPORT. Scientific and technical findings by NASA-sponsored contractors and grantees.
- CONFERENCE PUBLICATION. Collected papers from scientific and technical conferences, symposia, seminars, or other meetings sponsored or cosponsored by NASA.

- SPECIAl PUblicAtion. Scientific, technical, or historical information from NASA programs, projects, and missions, often concerned with subjects having substantial public interest.

- TECHNICAL TRANSLATION. Englishlanguage translations of foreign scientific and technical material pertinent to NASA's mission.

Specialized services that complement the STI Program Office's diverse offerings include creating custom thesauri, building customized data bases, organizing and publishing research results... even providing videos.

For more information about the NASA STI Program Office, see the following:

- Access the NASA STI Program Home Page at http://www.sti.nasa.gov

- E-mail your question via the Internet to help@sti.nasa.gov

- Fax your question to the NASA Access Help Desk at 301-621-0134

- Telephone the NASA Access Help Desk at 301-621-0390

- Write to:

NASA Access Help Desk NASA Center for AeroSpace Information 7121 Standard Drive

Hanover, MD 21076

,

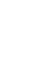


NASA/CR-2002-211344

ARL-CR-486
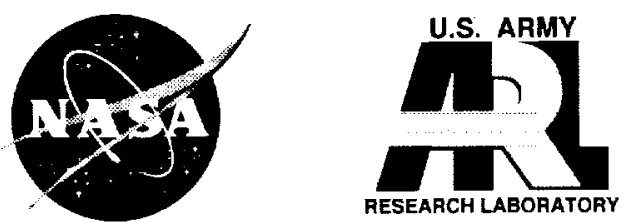

Design and Stress Analysis of Low-Noise Adjusted Bearing Contact Spiral Bevel Gears

Faydor L. Litvin and Alfonso Fuentes

University of Illinois at Chicago, Chicago, Ilinois

Baxter R. Mullins and Ron Woods

Bell Helicopter Textron, Inc., Fort Worth, Texas

Prepared under Grant NAG3-2450

National Aeronautics and

Space Administration

Glenn Research Center 


\section{Acknowledgments}

The authors express their deep gratitude to the Army Research Office, NASA Glenn Research Center, the Bell Helicopter Company, and the Gleason Foundation for their support of this research project.

Available from

NASA Center for Aerospace Information 7121 Standard Drive

Hanover, MD 21076
National Technical Information Service 5285 Port Royal Road Springfield, VA 22100

Available electronically at http://gltrs.grc.nasa.gov/GLTRS 


\title{
Design and Stress Analysis of Low-Noise Adjusted Bearing Contact Spiral Bevel Gears
}

\author{
Faydor L. Litvin ${ }^{*}$ and Alfonso Fuentes \\ Gear Research Center, Department of Mechanical Engineering \\ University of Illinois at Chicago \\ Chicago, Mlinois 60607-7022 \\ Baxter R. Mullins and Ron Woods \\ Bell Helicopter Textron, Inc. \\ Fort Worth, Texas 76101
}

\begin{abstract}
An integrated computerized approach for design and stress analysis of low-noise spiral bevel gear drives with adjusted bearing contact has been developed. The computation procedure is an iterative process, requiring four separate steps that provide: (a) a parabolic function of transmission errors that is able to reduce the effect of errors of alignment, and (b) reduction of the shift of bearing contact caused by misalignment. Application of finite element analysis permits the contact and bending stresses to be determined and investigate the formation of the bearing contact. The design of finite element models and boundary conditions is automated and does not require an intermediate CAD computer program. A commercially available finite element analysis computer program with contact capability was used to conduct the stress analysis. The theory developed is illustrated with numerical examples.
\end{abstract}

\section{Nomenclature}

$\alpha_{k}(k=g, p) \quad$ Blade angle of gear $(k=g)$ and pinion $(k=p)$ head-cutters

$\beta_{i}(i=0,1,2) \quad$ Coefficients of numerically obtained polynomial function for presentation of projection of path of contact on tangent plane $T$

$\gamma_{m_{i}}(i=1,2)$

Angles of pinion $(i=1)$ and gear $(i=2)$ root cones, respectively

$\eta_{i}(=1,2)$

Parameter for presentation of tangent to the path of contact on the pinion $(i=1)$ and gear $(i=2)$ tooth surfaces respectively

$\theta_{p}, \theta_{g}$

$\lambda_{f}, \lambda_{w}$

Surface parameters of the pinion and gear head cutters, respectively

Surface parameters of the pinion and gear fillet parts of the head cutter

$\psi_{c_{i}}(i=1,2)$

Angle of rotation of the cradle in the process for generation of the pinion $(i=1)$ or gear $(i=2)$

$\psi_{i}(i=1,2)$

Angle of rotation of the pinion $(i=1)$ or gear $(i=2)$ in the process for generation

$\rho_{f}, \rho_{w}$

Fillet radii for the pinion and the gear

$\omega^{(i)}(i=1,2)$

Angular velocity of the pinion $(i=1)$ or gear $(i=2)$ (in meshing and generation)

$\Sigma_{i}(i=1,2)$

Pinion $(i=1)$ or gear $(i=2)$ tooth surfaces

$\Sigma_{k}(k=p, g)$

Pinion $(k=p)$ or gear $(k=g)$ generating surfaces

"Corresponding author. Phone: 312-996-2866, Fax: 312-413-0447, E-mail: FLitvin@uic.edu 


$\begin{array}{ll}\Delta \phi_{2}\left(\phi_{1}\right) & \text { Function of transmission errors } \\ \Delta \Phi & \text { Maximal level of transmission errors } \\ \Delta A_{1}, \Delta A_{2} & \text { Pinion and gear axial displacements, respectively } \\ \Delta E, \Delta \gamma & \text { Offset and change of shaft angle due to errors of alignment, respectively } \\ \Delta E_{m_{i}} & \text { Blank offset of pinion }(i=1) \text { or gear }(i=2) \\ \Delta X_{B_{i}} & \text { Sliding base for pinion }(i=1) \text { or gear }(i=2) \\ \Delta X_{b_{i}} & \text { Machine center to back for pinion }(i=1) \text { or gear }(i=2) \\ a_{i}(i=0,1,2,3) & \text { Coefficients of polynomial functions } \Delta \phi_{2}\left(\phi_{1}\right) \text { of transmission errors } \\ L_{T} & \text { Projection of path of contact on the tangent plane } T \\ m_{21}^{\prime} & \text { Second derivative of transmission function } \phi_{2}\left(\phi_{1}\right) \\ m_{12} & \text { Gear ratio } \\ m_{1 c} & \text { Ratio of pinion roll } \\ m_{2 c_{2}} & \text { Ratio of gear roll } \\ M & \text { Mean contact point } \\ \mathbf{M}_{j i}, \mathbf{L} \mathbf{L}_{j i}, & \text { Matrices of coordinate transformation from system } S_{i} \text { to system } S_{j} \\ \boldsymbol{n}_{i}^{(k)}, N_{i}^{(k)} & \text { Unit normal and normal to surface } \Sigma_{k} \text { represented in coordinate system } S_{i} \\ q_{i}(i=1,2) & \text { Installment angle for head-cutter of the pinion }(i=1) \text { and gear }(i=2) \\ R_{p}, R_{g} & \text { Head-cutter point radius for the pinion and gear } \\ \boldsymbol{r}_{i} & \text { Position vector represented in system } S_{i}\left(i=1,2, b_{1}, b_{2}, h, l, m_{1}, m_{2}, p, g\right) \\ s_{p}, s_{g} & \text { Surface parameters of the pinion and gear } \\ S_{i} & \text { Coordinate system }\left(i=1,2, b_{1}, b_{2}, h, l, m_{1}, m_{2}, p, g\right) \\ S_{r_{i}}(i=1,2) & \text { Radial setting of the head-cutter of the pinion }(i=1) \text { and gear }(i=2) \\ \boldsymbol{v}^{(i j)} & \text { Relative velocity at contact point }\left(i, j=1,2, c_{1}, c_{2}, p, g\right)\end{array}$

\section{Introduction}

Spiral bevel gears have found broad application in helicopter, car and truck transmissions, reducers, etc. Design and stress analysis of such gear drives is a recent topic of research that has been performed by many scientists [1 - 6]. Reduction of noise and stabilization of bearing contact of misaligned spiral bevel gear drives is still a very challenging topic of research although the manufacturing companies (The Gleason Works (USA), Klingelnberg-Oerlikon (Germany-Switzerland)) have developed analysis tools and outstanding equipment for manufacture of such gear drives. The phenomenon of design of spiral bevel gears is that the machine-tool settings of spiral bevel gears are not standardized and have to be specially determined for each set of parameters of design, to guarantee the required quality of the gear drives.

A new approach is proposed for the solution of this problem that is based on the following considerations:

(1) The gear machine-tool settings are considered as given (adapted, for instance, from the Gleason summary). The to-be-determined pinion machine-tool settings have to provide the observation of assigned conditions of meshing and contact of the gear drive. 
(2) Low noise of the gear drive is achieved by application of a predesigned parabolic function of transmission errors of a limited value of maximum transmission error of 6-8 arcsec. A predesigned parabolic function of transmission errors is able to absorb almost linear discontinuous functions of transmission errors caused by errors of alignment. Such transmission errors are the source of high noise and vibration.

(3) The provided orientation of the bearing contact has to reduce its shift caused by the errors of alignment of the gear drive.

(4) The design procedure developed is an iterative process based on simultaneous application of local synthesis and TCA (Tooth Contact Analysis). The local synthesis provides assigned conditions of meshing and contact at the mean contact point of tangency of pinion-gear tooth surfaces. The TCA computer program can simulate the conditions of meshing and contact for the entire meshing process.

Finite element method (FEM) is used for stress analysis and the investigation of the bearing contact. A model of three contacting teeth complemented with the boundaries conditions is applied for the finite element analysis (FEA). The computer program applied for FEA can be found in Reference [7].

The contact models are automated and does not require application of CAD computer programs.

Computer programs for synthesis, analysis, and automation of FEA are based on application of the same programming language. Graphic representation of results of computation is obtained by application of a commercially available graphic library.

\section{Basic Ideas of Developed approach}

Local Synthesis. The mean contact point $M$ is chosen on gear tooth surface $\Sigma_{2}$ (Fig. 1). Parameters $2 a$, $\eta_{2}$, and $m_{12}^{\prime}$ are taken at $M$ and represent the mayor axis of the instantaneous contact ellipse, the tangent to the contact path on gear tooth surface, and the derivative of the gear ratio function $m_{12}=\omega^{(1)} / \omega^{(2)}$ where $\omega^{(1)}$ and $\omega^{(2)}$ are the angular velocities of the pinion and gear rotations. The local synthesis program determines the pinion machine-tool settings considering as known the gear machine-tool settings and parameters $a, \eta_{2}$, and $m_{12}^{\prime}$ [8]. The program requires solution of ten equations for ten unknowns but six of the ten equations are represented in echelon form. The algorithm of local synthesis includes relations between principal curvatures and directions proposed in [8 - 10].

TCA (Tooth Contact Analysis). The computer program algorithm is based on conditions of continuous tangency of pinion-gear tooth surfaces and is illustrated in Fig. 2. The TCA program determines the function of transmission errors $\Delta \phi_{2}\left(\phi_{1}\right)$ and the bearing contact obtained for each iteration when the input variable parameters $a, \eta_{2}$, and $m_{12}^{\prime}$ of the respective iteration are applied.

The computational procedure is divided into four separately applied procedures that are performed as follows: 
Procedure I: The purpose of the procedure is to obtain the assigned orientation of the bearing contact. The procedure is accomplished by the observation of the following conditions:

(a) The local synthesis and TCA are applied simultaneously whereas the variable parameter is $m_{12}^{\prime}$ and parameters $a$ and $\eta_{2}$ are taken as constant. The orientation of $\eta_{2}$ is initially chosen as a longitudinally oriented bearing contact. The errors of alignment are taken equal to zero.

(b) Using the output of TCA it becomes possible to obtain numerically the path of contact on gear tooth surface $\Sigma_{2}$ and determine its projection $L_{T}$ on plane $T$ that is tangent to $\Sigma_{2}$ at $M$ (Fig 1).

(c) The goal of the iterative process (accomplished by simultaneous application of local synthesis and TCA) is to obtain $L_{T}^{(n)}$ as the straight line for the process of meshing of the cycle $-\pi / N_{1} \leq \phi_{1} \leq \pi / N_{1}$. This goal is achieved by variation of $m_{12}^{\prime}$ and the sought-for solution is obtained analytically as follows:

(i) The numerically obtained projection $L_{T}^{(i)}$ is represented by a polynomial function

$$
y_{t}\left(x_{t}, m_{12}^{\prime(i)}\right)=\beta_{0}\left(m_{12}^{\prime}\right)^{(i)}+\beta_{1}\left(m_{12}^{\prime}\right)^{(i)} x_{t}+\beta_{2}\left(m_{12}^{\prime}\right)^{(i)} x_{t}^{2}
$$

(ii) Variation of $m_{12}^{\prime(i)}(i=1,2,3, \cdots, n)$ in the iterative process based on simultaneous application of local synthesis and TCA, enables obtaining a path of contact when $\beta_{2}=0$ and $L_{T}^{(n)}$ becomes a straight line. Fig. 3 shows various lines $L_{T}^{(1)}, L_{T}^{(2)}$ that might be obtained, and line $L_{T}^{(n)}$ of the desired shape.

(iii) The iterative process is directed at obtaining $\beta_{2}\left(m_{12}^{\prime}\right)^{(i)}$ and is based on the secant method [11] that is illustrated with Fig. 4.

Procedure 2: Procedure 1 is accomplished obtaining $L_{T}^{(n)}$ as a straight line. However, the output of the TCA for the function of the transmission errors, function $\Delta \phi_{2}^{(n)}\left(\phi_{1}\right)$ where $-\pi / N_{1} \leq \phi_{1} \leq \pi / N_{1}$, is of unfavorable shape and magnitude. The goal is to transform $\Delta \phi_{2}^{(n)}\left(\phi_{1}\right)$ into a parabolic function and limit the magnitude of maximum transmission errors. This goal is achieved by application of modified roll for pinion generation.

Modified roll means that during the pinion generation the angles of rotation of the pinion and the cradle of the generating machine, designated as $\psi_{1}$ and $\psi_{c 1}$, respectively, are related as

$$
\psi_{1}^{(j)}\left(\psi_{c 1}\right)=m_{1 c} \psi_{c 1}-b_{2} \psi_{c 1}^{(2)}-b_{3} \psi_{c 1}^{(3)}
$$

Here $m_{1 c}$ is the first derivative of function $\psi_{1}\left(\psi_{c 1}\right)$ at $\psi_{c 1}=0$ that is obtained by application of local synthesis [4]. The superscript $j$ in Eq. (2) indicates that the $j$-th iteration is considered. 
The purpose of procedure 2 is the transformation of the function of transmission errors $\Delta \phi_{2}^{(n)}\left(\phi_{1}\right)$ obtained at the final step of Procedure 1. This goal is achieved as follows:

(i) The local synthesis and TCA computer program are applied simultaneously and the errors of alignment of the gear drive are taken equal to zero.

(ii) The function of transmission errors $\Delta \phi_{2}^{(n)}\left(\phi_{1}\right)$ is the output of TCA obtained at the $n$-th iteration of Procedure 1 and is represented numerically. We represent $\Delta \phi_{2}^{(n)}\left(\phi_{1}\right)$ as a polynomial function of the third order designated as

$$
\Delta \phi_{2}^{(j)}\left(\phi_{1}\right)=a_{0}^{(j)}+a_{1}^{(j)} \phi_{1}+a_{2}^{(j)} \phi_{1}^{2}+a_{3}^{(j)} \phi_{1}^{3}, \quad-\frac{\pi}{N_{1}} \leq \phi_{1} \leq \frac{\pi}{N_{1}}
$$

The designation $j=1,2, \cdots, k$ means that an iterative process for modification of $\Delta \phi_{2}^{(n)}\left(\phi_{1}\right)$ is considered. Function $\Delta \phi_{2}^{(1)}\left(\phi_{1}\right) \equiv \Delta \phi_{2}^{(n)}$ is obtained at the final iteration of Procedure 1 .

(iii) The goal of Procedure 2 is to transform the function of transmission errors and obtain

$$
\begin{gathered}
\Delta \phi_{2}^{(k)}\left(\phi_{1}\right)=-a_{2}^{(k)} \phi_{1}^{2}, \quad-\frac{\pi}{\mathrm{N}_{1}} \leq \phi_{1} \leq \frac{\pi}{\mathrm{N}_{1}} \\
\left|\Delta \phi_{2}^{(k)}\left(\phi_{1}\right)\right|_{\max }=a_{2}^{(k)}\left(\frac{\pi}{N_{1}}\right)^{2}=\Delta \Phi
\end{gathered}
$$

(iv) The goals mentioned above are obtained by variation of coefficients $b_{2}^{(j)}$ and $b_{3}^{(j)}$ of the function of modified roll. The secant method is applied for this purpose whereas variations of $b_{2}^{(j)}$ and $b_{3}^{(j)}$ are performed separately and illustrated in Fig. 5.

Procedure 3: Procedures 1 and 2 discussed above enable to obtain: (i) a longitudinally oriented projection $L_{T}$ of the path of contact and represent $L_{T}$ is a straight line; (ii) a parabolic function of transmission errors with the assigned level of maximum transmission errors. However, these results have been obtained for an aligned gear drive.

The goal of Procedure 3 is to reduce the shift of the bearing contact caused by errors of alignment and this is achieved by the proper change of orientation of $L_{T}$ assigned initially in Procedure 1.

Errors of alignment of the gear drive will cause the shift of the bearing contact but they will not affect the obtained function of transmission errors since it is a parabolic function that is able to absorb the linear functions of transmission errors caused by misalignment [8 - 10, 12] 
Procedure 3 is performed as follows:

(i) Computer programs developed for local synthesis and TCA are again applied simultaneously, but the expected errors of alignment are simulated.

(ii) The effect of all errors of alignment on the shift of the bearing contact is investigated separately. The sensitivity of the shift of $L_{T}$ is reduced by the proper choice of parameter $\eta_{2}$ (Fig. 1). Thus, the variable parameter of the local synthesis in Procedure 3 is $\eta_{2}$.

(iii) Application of procedure 3 causes the resultant $L_{T}$ to be different from the longitudinally one. The deviation depends on the parameters of the gear drive to be designed, particularly of the gear ratio $m_{12}$ (see Section 6), and on the errors of alignment that are applied.

Procedure 4: After completion of Procedures 1, 2, and 3, the obtained pinion machine-tool settings guarantee that the designed gear drive is indeed a low-noise gear drive with reduced sensitivity to errors of alignment (see numerical examples in Section 6).

The goal of Procedure 4 is the stress analysis and the investigation of formation of the bearing contact whereas the contact ratio is $m_{c}>1$ (see Section 5). The approach developed for finite element analysis (FEA) has the following advantages:

(1) The computer language applied for automation of FEA is the same as applied for the synthesis and analysis of the gear drive.

(2) The contacting model (formed by three teeth of the pinion and the gear and the boundary conditions) is determined automatically. There is no need in application of intermediate CAD computer programs to build the finite element models for application of FEA (see details in Section 5).

\section{Derivation of Equations of Gear Tooth Surfaces}

Introduction. Remember at this point that the machine-tool settings for the gear are considered as given and the to-be-derived equations allow the gear tooth surfaces to be determined. The head-cutter is provided with blades that are rotated about the $Z_{g}$-axis of the head-cutter (Fig. 6) during the process of generation. Both sides of the gear tooth are generated simultaneously. The profile of the blade consists of two parts (Fig. 6): (i) of a straight line, and (ii) of a fillet formed by two circular arcs connected by a straight line. The blades by rotation about the $Z_{g}$-axis form the head-cutter generating surfaces.

Applied Coordinate Systems. Coordinate system $S_{m_{2}}, S_{a_{2}}, S_{b_{2}}$ are the fixed ones and they are rigidly connected to the cutting machine (Fig. 7). The movable coordinate systems are $S_{2}$ and $S_{c_{2}}$ rigidly connected to the gear and the cradle, respectively. Coordinate system $S_{g}$ is rigidly connected to the gear head-cutter. It is considered that the head-cutter is a cone, and the rotation of the head cutter about the $Z_{g}$ axis does not affect the process of generation. The head-cutter is mounted on the cradle and coordinate system $S_{g}$ is rigidly connected to the cradle coordinate system $S_{c_{2}}$. The cradle and the gear perform related 
rotations about the $S_{m_{2}}$-axis and the $S_{b_{2}}$-axis, respectively. Angles $\psi_{c 2}$ and $\psi_{2}$ are related and represent the current angles of rotation of the cradle and the gear. The ratio of gear roll is designated as $m_{2 c_{2}}$ and is determined as

$$
m_{2 c_{2}}=\frac{\omega^{(2)}}{\omega^{\left(c_{2}\right)}}=\frac{d \psi_{2}}{d t}+\frac{d \psi_{c 2}}{d t}
$$

The installment of the tool on the cradle is determined by parameters $S_{r_{2}}$ and $q_{2}$, that are called radial distance and basic cradle angle. Parameters $\Delta X_{B_{2}}, \Delta E_{m_{2}}, \Delta X_{D_{2}}$ and $\gamma_{m_{2}}$ represent the settings of the gear. Figs. 7(a) and 7(b) show the installment of the head-cutter for right hand and left hand gears, respectively.

Procedure of Derivation. The head-cutter generating surface is represented in coordinate system $S_{g}$ by the vector function $r_{g}\left(s_{g}, \theta_{g}\right)$ where $s_{g}$ and $\theta_{g}$ are the surface parameters.

The family of generating surfaces is represented in coordinate system $S_{2}$ rigidly connected to the gear by the matrix equation

$$
r_{2}\left(s_{g}, \theta_{g}, \psi_{2}\right)=\mathbf{M}_{2 g}\left(\psi_{2}\right) r_{g}\left(s_{g}, \theta_{g}\right)
$$

where $\psi_{2}$ is the generalized parameter of motion.

The equation of meshing is represented as

$$
f_{2 g}\left(s_{g}, \theta_{g}, \psi_{2}\right)=0
$$

is determined as $[8,10]$

$$
\left(\frac{\partial r_{2}}{\partial \theta_{g}} \times \frac{\partial r_{2}}{\partial s_{g}}\right) \cdot \frac{\partial r_{2}}{\partial \psi_{2}}=0
$$

or as $[8-10]$

$$
N_{g} \cdot v_{g}^{(g 2)}=0
$$

Here $N_{g}\left(s_{g}, \theta_{g}\right)$ is the normal to the head-cutter surface represented in coordinate system $S_{g}$ and $v_{g}^{\left(g^{2}\right)}$ is the relative velocity represented in $S_{g}$.

Equations (7) and (8) determine the gear tooth surface by three related parameters. 


\section{Derivation of Pinion Tooth Surfaces}

Introduction. The two sides of the pinion tooth surfaces are generated separately. The machine-tool settings applied for generation of each tooth side are determined separately, by application of Procedures 1 , 2 , and 3 mentioned above.

Profile blades of pinion head-cutters are represented in Fig. 8.

Applied Coordinate Systems. Coordinate systems applied for generation of pinion are shown in Fig. 9. Coordinate systems $S_{m_{1}}, S_{a_{1}}, S_{b_{1}}$ are the fixed ones and they are rigidly connected to the cutting machine.

The movable coordinate systems $S_{1}$ and $S_{c_{1}}$ are rigidly connected to the pinion and the cradle, respectively. Systems $S_{1}$ and $S_{2}$ are rotated about the $Z_{m_{1}}$-axis and $Z_{b_{1}}$-axis, respectively, and their rotations are related by a polynomial function $\psi_{1}\left(\psi_{c 1}\right)$ wherein modified roll is applied (see below). The ratio of instantaneous angular velocities of the pinion and the cradle is defined as $m_{1 c}\left(\psi_{1}\left(\psi_{c l}\right)\right)=\omega^{(1)}\left(\psi_{c 1}\right) / \omega^{(c)}$. The magnitude $m_{1 c}\left(\psi_{1}\right)$ at $\psi_{c 1}$ is called ratio of roll or velocity ratio. Parameters $\Delta X_{D_{1}}, \Delta X_{B_{1}}, \Delta E_{m_{1}}, \gamma_{m_{1}}$ are the basic machine tool settings for pinion generation.

Procedure of Derivation. The pinion head-cutter surface is represented by vector function $\boldsymbol{r}_{p}\left(s_{p}, \theta_{p}\right)$ (Fig. 8) where $\left(s_{p}, \theta_{p}\right)$ are the surface parameters.

The family of head-cutters is represented in coordinate system $S_{1}$ rigidly connected to the pinion by the matrix equation

$$
r_{1}\left(s_{p}, \theta_{p}, \psi_{c l}\right)=\mathbf{M}_{1 p}\left(\psi_{c l}\right) r_{p}\left(s_{p}, \theta_{p}\right)
$$

Unlike the case of gear generation, modified roll is applied for the generation of the pinion, and function $\psi_{1}\left(\psi_{c l}\right)$ relates the angles of rotation of the pinion and the cradle of the pinion generating machine by a polynomial but not linear function (see Eq. (2)).

The equation of meshing is determined as

$$
f_{p 1}\left(s_{p}, \theta_{p}, \psi_{c 1}\right)=0
$$

that is derived by application of two following alternative approaches [ $8-10]$ :

$$
\left(\frac{\partial r_{1}}{\partial \theta_{p}} \times \frac{\partial r_{1}}{\partial s_{p}}\right) \cdot \frac{\partial r_{1}}{\partial \psi_{c 1}}=0
$$

or

$$
N_{p} \cdot v_{p}^{(p 1)}=0
$$


where $N_{p}$ is the normal to pinion head-cutter surface $\Sigma_{p}$ that is represented in $S_{p}$.

Equations (11) and (12) represent the pinion tooth surfaces by three related parameters.

\section{Application of Finite Element Analysis}

Application of finite element analysis permits the following:

(1) Investigation of the bearing contact when multiple sets of teeth may be in contact under load simultaneously.

(2) Determination of the contact and bending stresses.

Application of finite element method [13] requires the development of the finite element model mesh, the definition of possible contacting surfaces, and the establishment of boundary conditions to load the gear drive with the desired torque. Finite element analysis is performed by application of general purpose computer program [7].

The authors have developed a modified approach to perform the finite element analysis that has the following advantages:

(a) The same programming language is applied for synthesis, analysis and generation of finite element models of the gear drives. Graphical interpretation of the output is obtained by using commercially available graphical subroutines.

(b) The generation of the finite element mesh required for FEA is performed automatically using the equations of the surfaces of the tooth and its portion of the rim. Nodes of the finite element mesh lying on the sections of tooth surfaces of pinion (gear) are guaranteed to be points of the real tooth surfaces of the pinion (gear). Loss of accuracy due to the development of solid models using CAD computer programs is avoided. The boundary conditions for the pinion and the gear are set automatically as well.

(c) Investigation of the bearing contact for a cycle of meshing permits investigation of the influence of the contact ratio $m_{c}$ (whereas the contact is formed on neighboring tooth surfaces if $m_{c}>1$ ) and find out the possibility of edge contact.

(d) There is no need to apply CAD computer programs for development of finite element models for finite element analysis.

The development of the solid models and finite element meshes using CAD computer programs is expensive, requires skilled users of used computer programs, and has to be done for every case of gear geometry and position of meshing to be investigated.

The developed approach is free of all these disadvantages and is summarized as follows:

Step 1: Using the equations of both sides of tooth surfaces and the portions of the corresponding rim, we may represent analytically the volume of the designed body. Fig. 10(a) shows the designed body for onetooth model of the pinion of a spiral bevel gear drive. 
Step 2: Auxiliary intermediate surfaces 1 to 6 shown in Fig. 10(b) may be determined. Surfaces 1 to 6 enable to divide the tooth in six volume sectors and control the discretization of these tooth subvolumes into finite elements.

Step 3: Analytical determination of node coordinates is performed taking into account the number of desired elements in longitudinal and profile direction (Fig. 10(c)). We emphasize that all nodes of the finite element mesh are determined analytically and those lying on the tooth surfaces are indeed points belonging to the real surfaces.

Step 4: Discretization of the model by finite elements using nodes determined in previous step is accomplished as shown in Fig. 10(d).

Step 5: Setting of boundary conditions for gear and pinion is automatic. Nodes on the sides and bottom part of the rim portion of the gear are considered fixed (Fig. 11(a)). Nodes on the two sides and bottom part of the rim portion of the pinion build a rigid surface (Fig. 11(b)). Rigid surfaces are three-dimensional geometric structures that cannot be deformed but can perform translation or rotation as rigid bodies. They are also very cost-effective in time since the variables associated with a rigid surface are the translations and rotations of a single node, known as the rigid body reference node (Fig. 11(b)). The rigid body reference node is located on the pinion axis of rotation with all degrees of freedom except the rotation around the axis of rotation of the pinion fixed to zero. The torque is applied directly to the remaining degree of freedom of the rigid body reference node (Fig. 1 I(b)).

Step 6: Definition of contacting surfaces for the contact algorithm of the finite element computer program [7] is automatic as well and requires definition of the master and slave surfaces. Generally, the master surface is chosen as the surface of the stiffer body or as the surface with the coarser mesh if the two surfaces are located on structures with comparable stiffness. Finite element mesh for the pinion is more refined than the one for the gear due to larger curvatures. The gear and pinion tooth surfaces are considered as the master and slave surfaces, respectively, for the contact algorithm.

\section{Numerical Examples}

Three examples of design of face-milled spiral bevel gears with different design parameters have been accomplished for the illustration of the developed theory. Details of the examples of design are represented in Tables 1 to 4.

The output from the computations for the examples given are represented in Fig. 12 that shows:

(i) The bearing contact has a longitudinal direction in Example 1 for an aligned gear drive (Fig. 12(a)).

(ii) The bearing contact in Example 2 (Fig. 12(b)) is deviated from the longitudinal direction to reduce the shift of bearing contact caused by errors of alignment (see Table 5).

(iii) Example 3 of design (Fig. 12(c)) shows that the gear drive with a gear ratio close to $1\left(N_{2} / N_{1}=26 / 17\right)$ is very sensitive to errors of alignment. The shift of bearing contact due to misalignment is reduced by larger deviation of the bearing contact from the longitudinal direction (see Table 5).

(iv) The function of transmission errors (Fig. 12(d)) for all three examples is indeed a parabolic function up to 8 arcsec of maximum amount. 
Finite element analysis has been performed for all three examples. Fig. 13 shows the three-pair-of-teeth finite element mesh for example 2. Fig. 14 shows the whole gear drive finite element mesh.

Application of finite element analysis enables permits the investigation of the bearing contact during the cycle of meshing. Fig. 15 shows the formation of the bearing contact in example 2 at the heel position of the gear.

\section{Conclusions}

Based on the study conducted, the following conclusions can be made:

(1) An integrated computerized approach has been developed for design of low-noise spiral bevel gears with an adjusted bearing contact based on the following ideas:

(i) A parabolic function of transmission errors of limited value of maximum transmission errors is applied. This permits linear discontinuous functions of transmission errors caused by misalignment to be absorbed.

(ii) The orientation of the bearing contact is adjusted to reduce the shift of contact caused by errors of alignment.

(iii) The approach developed is an iterative procedure based on simultaneous application of local synthesis and TCA (Tooth Contact Analysis) using modified roll for pinion generation.

(iv) The contacting model for finite element analysis is formed by three teeth and the boundary conditions, it is automatically designed and does not need intermediate CAD computer programs for application of finite element analysis.

(v) The same computer language is applied for numerical computations performed for all stages of design, and automatic generation of finite element models.

(2) The approach developed may also be applied for design of format cut spiral bevel gears, hypoid gear drives and other gear drives.

\section{References}

1 Handschuh, R.F. and Litvin, F.L., 1991, "A method for Determining Spiral-Bevel Gear Tooth Geometry for Finite Element Analysis," NASA Technical Paper 3096, AVSCOM Technical Report 91-C-020.

2 Lewicki, D.G., Handschuh, R.F., Henry, Z.S., and Litvin, F.L., 1994, "Low-Noise, High Strength Spiral Bevel Gears for Helicopter Transmission,” J. Propul. Power, Vol. 10, No. 3.

3 Litvin, F.L., Egelja, A., Tan, J., and Heath, G., 1998, "Computerized Design, Generation and Simulation of Meshing of Orthogonal Offset Face-Gear. Drive with a Spur Involute Pinion with Localized Bearing Contact," Mechanism and Machine Theory, Vol. 33, pp. 87-102. 
4 Litvin, F.L., Wang, A.G., and Handschuh, R.F., 1996, "Computerized Design and Analysis of Face-Milled Uniform Tooth Height Spiral Bevel Gear Drives," ASME Journal of Mechanical Design, Vol. 118, No. 4, pp. 573-579.

5 Stadtfeld, H.J., 1993, "Handbook of Bevel and Hypoid Gears: Calculation, Manufacturing, and Optimization," Rochester Institute of Technology, Rochester, New York.

6 Stadtfeld, H.J., 1995, "Gleason Bevel Gear Technology - Manufacturing, Inspection and Optimization, Collected Publications," The Gleason Works, Rochester, New York.

7 Hibbit, Karlsson, and Sorensen, Inc., 1998, "ABAQUS/Standard 6.1 User's Manual," 1800 Main Street, Pantucket, RI 20860-4847.

8 Litvin, F.L., 1994, "Gear Geometry and Applied Theory," Prentice Hall, Inc., Englewood Cliffs, New Jersey.

9 Litvin, F.L., 1968, "Theory of Gearing," Nauka (in Russian), Moscow.

10 Litvin, F.L., 1989, "Theory of Gearing," NASA RP-1212 (AVSCOM 88-C-C035), Washington, D.C.

11 Press, W.H., Teukolsky, S.A., Vetterling, W.T., and Flannery, B.P., 1992, "Numerical Recipes in Fortran 77: The Art of Scientific Computing," Cambridge University Press, New York, 2nd Ed.

12 Litvin, F.L., 1998, "Development of Gear Technology and Theory of Gearing," NASA Reference Publication 1406, ARL-TR-1500.

13 Zienkiewicz, O.C. and Taylor, R.L., 2000, "The Finite Element Method," John Wiley \& Sons, 5th Ed. 
Table 1: Blank data

\begin{tabular}{|c|c|c|c|c|}
\hline & \multicolumn{2}{|c|}{ Examples 1, 2} & \multicolumn{2}{|c|}{ Example 3} \\
\hline & Pinion & $\overline{\text { Gear }}$ & Pinion & Gear \\
\hline $\begin{array}{l}\text { Number of teeth of the pinion and } \\
\text { gear }\end{array}$ & 20 & $\overline{443}$ & 17 & 26 \\
\hline Diametral pitch $(1 / \mathrm{mm})$ & \multicolumn{2}{|c|}{0.1676} & \multicolumn{2}{|c|}{0.2600} \\
\hline Shaft angle (deg.) & \multicolumn{2}{|c|}{90.0000} & \multicolumn{2}{|c|}{90.0000} \\
\hline Mean spiral angle (deg.) & 32.0000 & 32.0000 & 30.0000 & 30.0000 \\
\hline Hand of spiral & RH & LH & LH & RH \\
\hline Face width (mm) & 41.0000 & 41.0000 & 20.3700 & 20.3700 \\
\hline Mean cone distance $(\mathrm{mm})$ & 120.9400 & 120.9400 & 49.5600 & 49.5600 \\
\hline Whole depth (mm) & 11.2600 & 11.2600 & 8.4400 & 8.4400 \\
\hline Pitch angles (deg.) & 24.9439 & 65.0561 & 33.1785 & 56.8215 \\
\hline Root angles (deg.) & 23.1666 & 61.8166 & 30.4500 & 51.4000 \\
\hline Face angles (deg.) & 28.1833 & 66.8333 & 38.6000 & 59.5500 \\
\hline Clearance $(\mathrm{mm})$ & 1.1200 & 1.1200 & 0.9100 & 0.9100 \\
\hline Addendum (mm) & 6.8900 & 3.2500 & 5.0200 & 2.5100 \\
\hline Dedendum (mm) & 4.3700 & 8.0100 & 3.4200 & 5.9300 \\
\hline
\end{tabular}

Table 2: Parameters and installment settings of the gear head-cutter

\begin{tabular}{l|r|r}
\hline & Examples 1, 2 & Example 3 \\
\hline Average cutter diameter $R_{u 2}$ (mm) (Fig. 6) & 152.4000 & 44.4500 \\
Point width $P_{w 2}$ (mm) (Fig. 6) & 3.5560 & 1.7780 \\
Pressure angle, concave $\alpha_{g}$ (outside blade) (deg.) (Fig. 6) & 20.0000 & 20.0000 \\
Pressure angle, convex $\alpha_{g}$ (inside blade) (deg.) (Fig. 6) & 20.0000 & 25.0000 \\
Root fillet radius, concave and convex $\rho_{u^{\prime}}$ (mm) (Fig. 6) & 2.4130 & 1.1430 \\
Machine center to back $\Delta X_{D_{2}}$ (mm) (Fig. 7) & 0.0000 & 0.0000 \\
Sliding base $\Delta X_{B_{2}}$ (mm) (Fig. 7) & 0.0000 & 0.2000 \\
Blank offset $\Delta E_{m_{2}}$ (mm) (Fig. 7) & 0.0000 & 0.0000 \\
Radial distance $S_{r_{2}}$ (mm) (Fig. 7) & 135.2870 & 53.5653 \\
Machine root angle $\gamma_{m_{2}}$ (deg.) (Fig. 7) & 61.8166 & 51.4000 \\
Cradle angle $q_{2}$ (deg.) (Fig. 7) & 72.8081 & 54.3532 \\
Velocity ratio $m_{2 c_{2}}$ & 1.1011 & 1.2250 \\
\hline
\end{tabular}


Table 3: Parameters and installment settings of the pinion head-cutter

\begin{tabular}{l|rr|rr|rr}
\hline & \multicolumn{2}{|c|}{ Example 1 } & \multicolumn{2}{c|}{ Example 2 } & \multicolumn{2}{c}{ Example 3 } \\
\hline Cutter point diameter $R_{p}$ (mm) (Fig. 8) & \multicolumn{1}{|c|}{ Concave } & \multicolumn{1}{c|}{ Convex } & Concave & \multicolumn{1}{c}{ Convex } & \multicolumn{1}{c}{ Concave } & Convex \\
Pressure angle $\alpha_{p}$ (deg.) (Fig. 8) & 152.7502 & 152.2802 & 152.6964 & 152.3493 & 40.4643 & 48.2959 \\
Root fillet radius $\rho_{f}$ (mm) (Fig. 8) & 1.0160 & 1.0160 & 1.0160 & 1.0160 & 0.7620 & 0.7620 \\
Machine center to back $\Delta X_{D_{1}}(\mathrm{~mm})$ (Fig. 8) & 2.2268 & -1.7319 & 2.2066 & -1.8271 & -1.2392 & 0.7604 \\
Sliding base $\Delta X_{B_{1}}$ (mm) (Fig. 9) & -0.8572 & 0.7002 & -0.8492 & 0.7376 & 0.0559 & -0.9574 \\
Blank offset $\Delta E_{m_{1}}$ (mm) (Fig. 9) & 11.4197 & -11.8235 & 7.7182 & -6.8138 & 1.8219 & -1.5402 \\
Radial distance $S_{\eta}$ (mm) (Fig. 9) & 125.3700 & 145.6443 & 128.8831 & 140.9091 & 52.1695 & 55.2535 \\
Machine root angle $\gamma_{m 1}$ (deg.) (Fig. 9) & 23.1666 & 23.1666 & 23.1666 & 23.1666 & 30.4500 & 30.4500 \\
Cradle angle $q_{1}$ (deg.) (Fig. 9) & 73.0017 & 71.9026 & 73.4721 & 71.3245 & -54.5158 & -44.4546 \\
Velocity ratio $m_{1 c}$ & 2.2467 & 2.4848 & 2.2941 & 2.4260 & 1.8286 & 1.9251 \\
Coefficient $b_{2}$ of modified roll (Eq. (2)) & 0.00011 & -0.00012 & 0.00006 & -0.00005 & -0.00002 & -0.00013 \\
Coefficient $b_{3}$ of modified roll (Eq. (2)) & 0.02845 & -0.03079 & 0.01772 & -0.01579 & 0.00582 & -0.00852 \\
\hline
\end{tabular}

Table 4: Parameters for local synthesis

\begin{tabular}{|c|c|c|c|c|c|c|}
\hline & \multicolumn{2}{|c|}{ Example 1} & \multicolumn{2}{|c|}{ Example 2} & \multicolumn{2}{|l|}{ Example 3} \\
\hline & Concave & Convex & Concave & Convex & Concave & Convex \\
\hline Direction of path of contact $\eta_{2}$ (deg.) (Fig. 1) & 154.0000 & 171.0000 & 152.0000 & 168.0000 & 148.0000 & 155.0000 \\
\hline Length major axis contact ellipse $2 a(\mathrm{~mm})$ (Fig. 1) & 12.0000 & 12.0000 & 12.0000 & 12.0000 & 8.0000 & 9.0000 \\
\hline Derivative of gear ratio function $m_{12}$ & 0.003144 & -0.003144 & 0.003144 & -0.002555 & -0.002555 & 0.002555 \\
\hline Elastic approach $\delta(\mathrm{mm})$ & 0.00635 & 0.00635 & 0.00635 & 0.00635 & 0.00635 & 0.00635 \\
\hline
\end{tabular}

Table 5: Errors of alignment allowed in examples 2 and 3

\begin{tabular}{|l|c|c|c|c|}
\hline & \multicolumn{2}{|c|}{ Example 2 } & \multicolumn{2}{c|}{ Example 3 } \\
\hline & Maximum & Minimum & Maximum & Minimum \\
\hline Axial displacement of the pinion, $\Delta A_{1}$ & $0.320 \mathrm{~mm}$ & $-0.350 \mathrm{~mm}$ & $0.100 \mathrm{~mm}$ & $-0.060 \mathrm{~mm}$ \\
\hline Axial displacement of the gear, $\Delta A_{2}$ & $0.250 \mathrm{~mm}$ & $-0.150 \mathrm{~mm}$ & $0.200 \mathrm{~mm}$ & $-0.150 \mathrm{~mm}$ \\
\hline Change of shaft angle, $\Delta \gamma$ & $1.000 \mathrm{deg}$. & $-0.800 \mathrm{deg}$. & $1.000 \mathrm{deg}$. & $-1.000 \mathrm{deg}$. \\
\hline Shortest distance between axes, $\Delta E$ & $0.150 \mathrm{~mm}$ & $-0.100 \mathrm{~mm}$ & $0.100 \mathrm{~mm}$ & $-0.100 \mathrm{~mm}$ \\
\hline
\end{tabular}




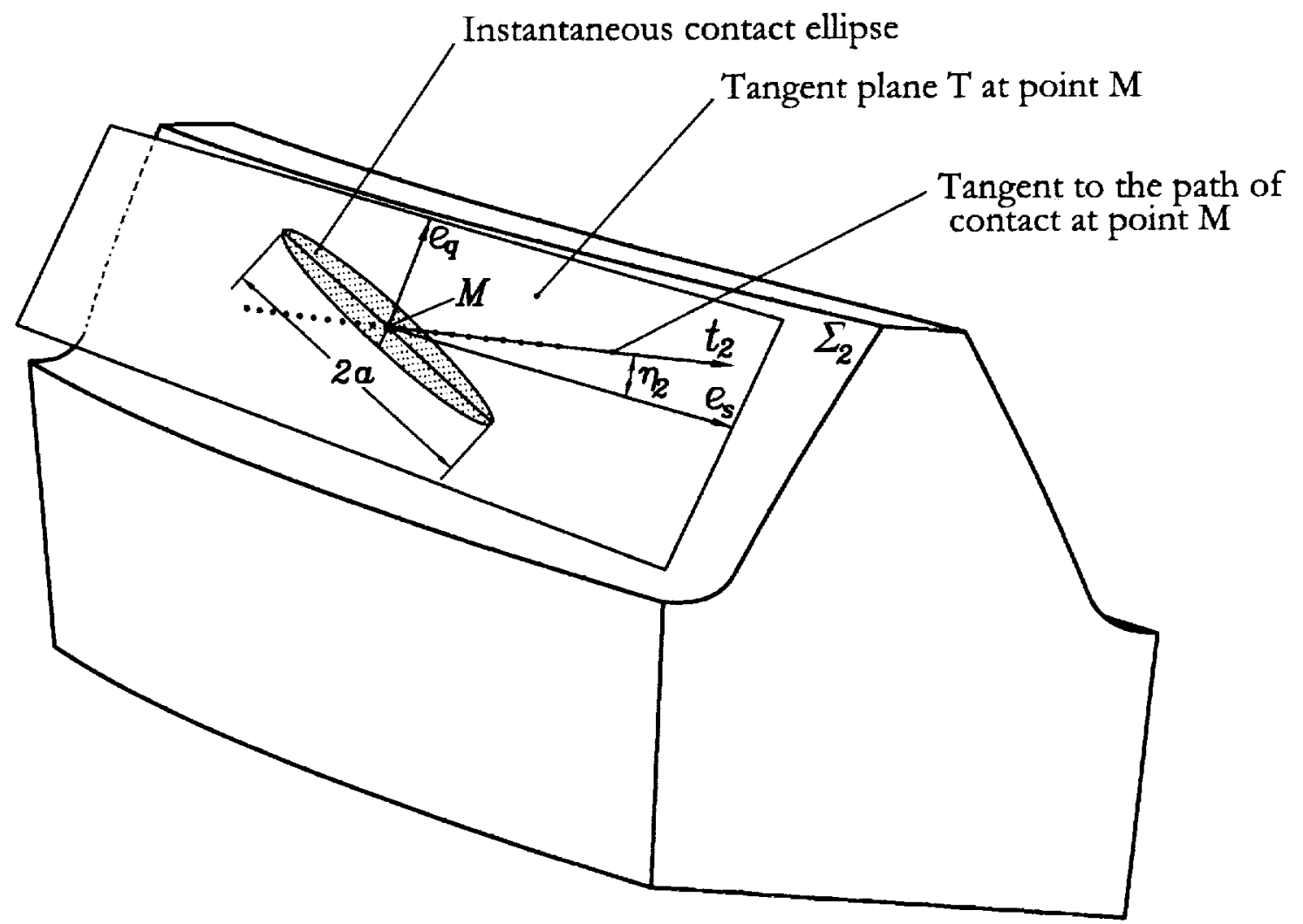

Figure 1.-Illustration of parameters $\eta_{2}$ and $a$ applied for local synthesis. 


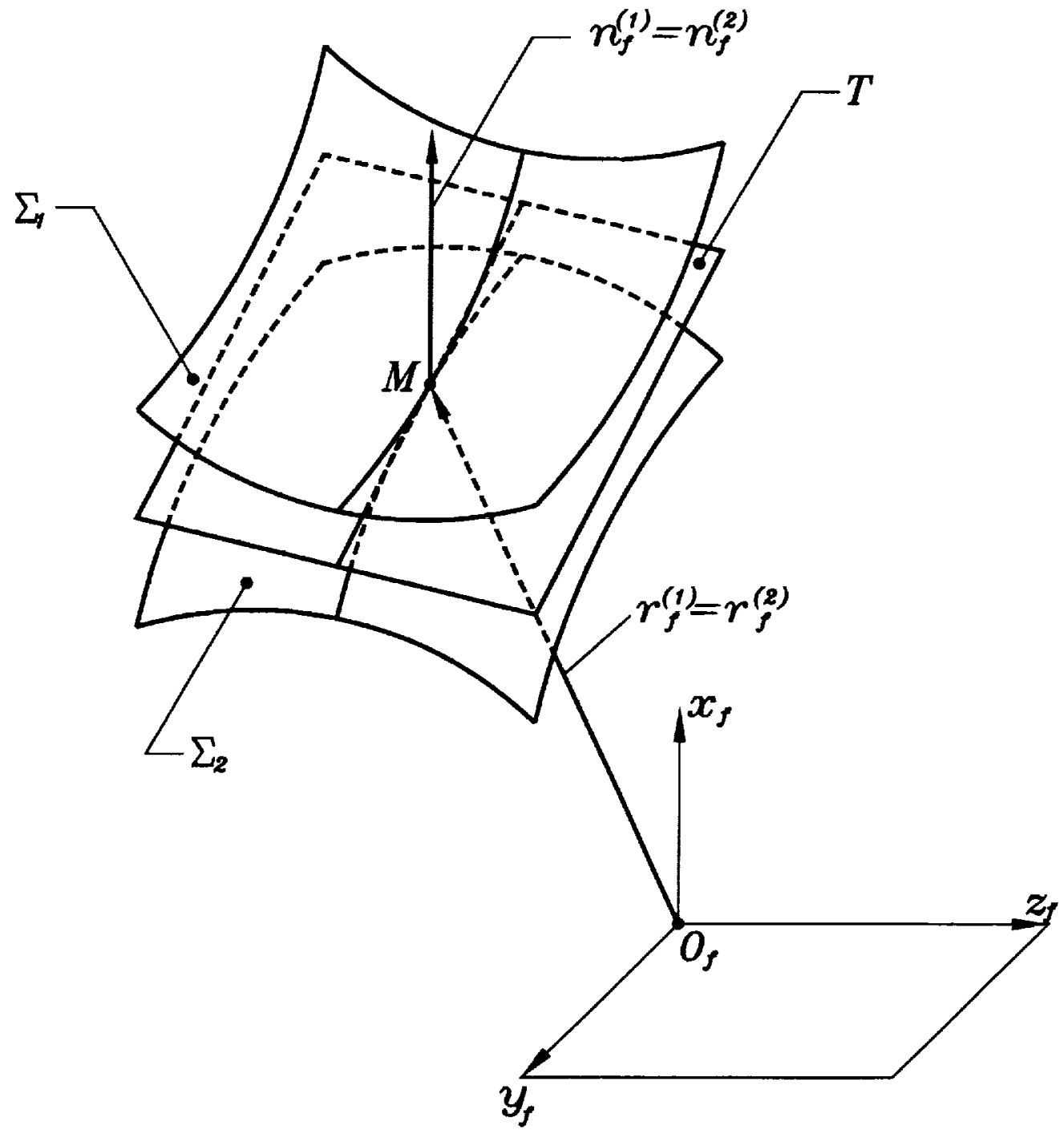

Figure 2.-Tangency of tooth surfaces of a gear drive. 


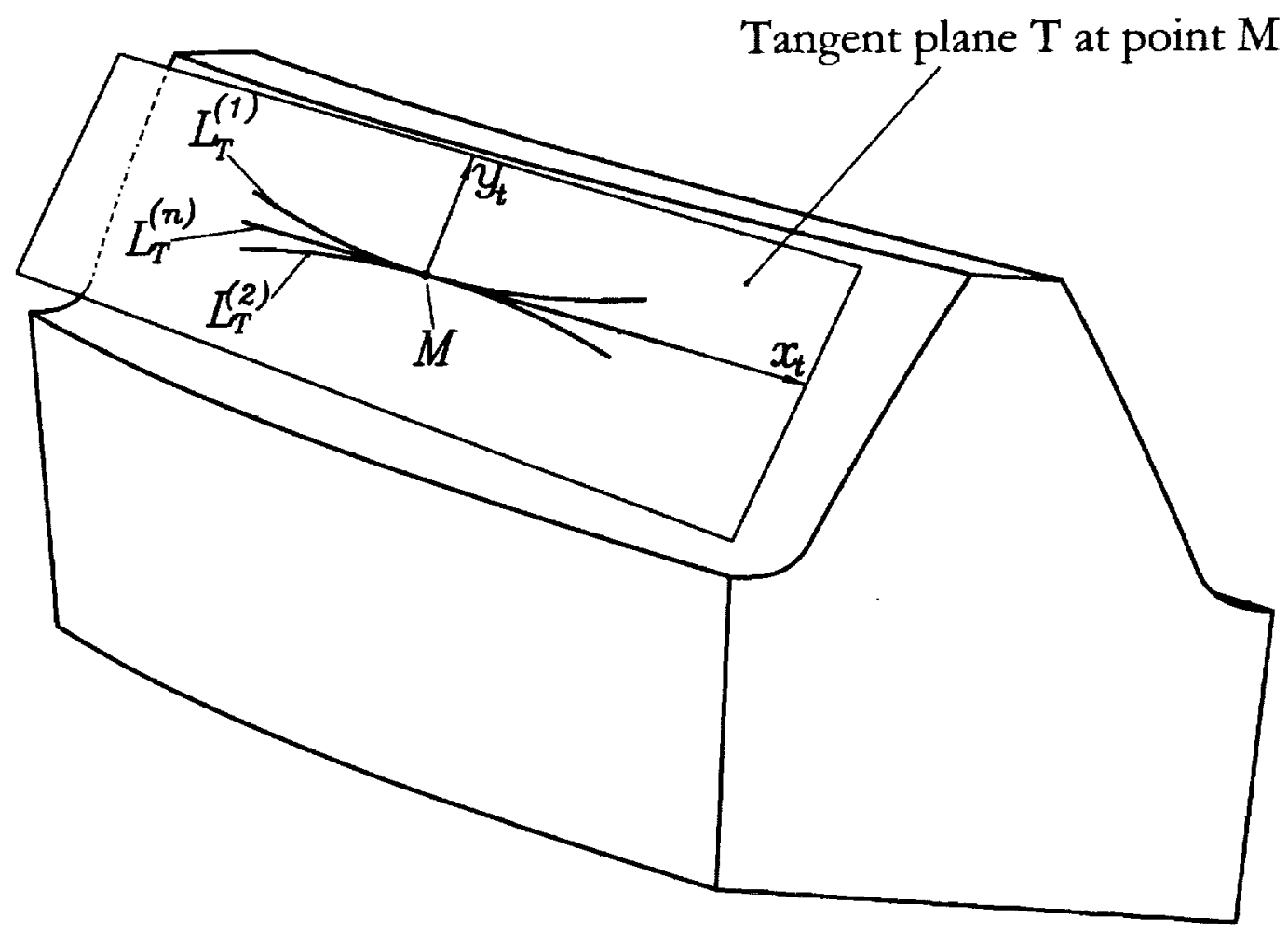

Figure 3.- Projections of various path of contact $L_{T}$ on tangent plane $T$. 


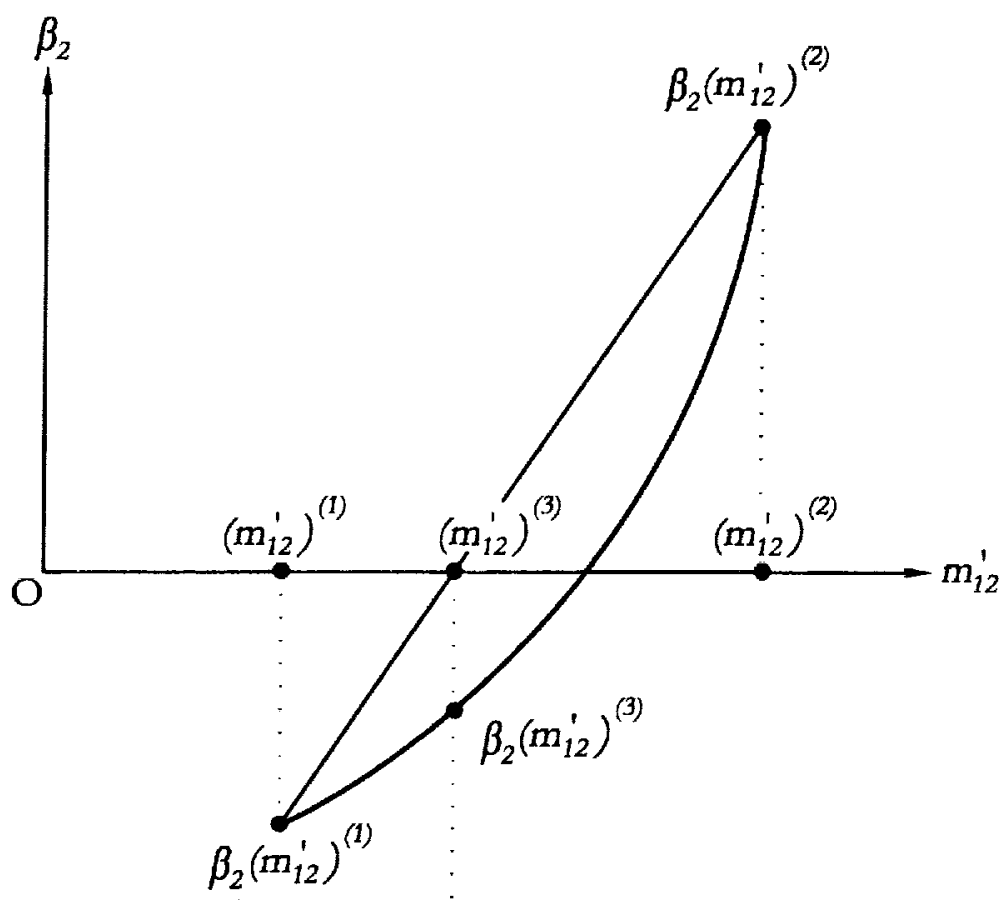

(a)

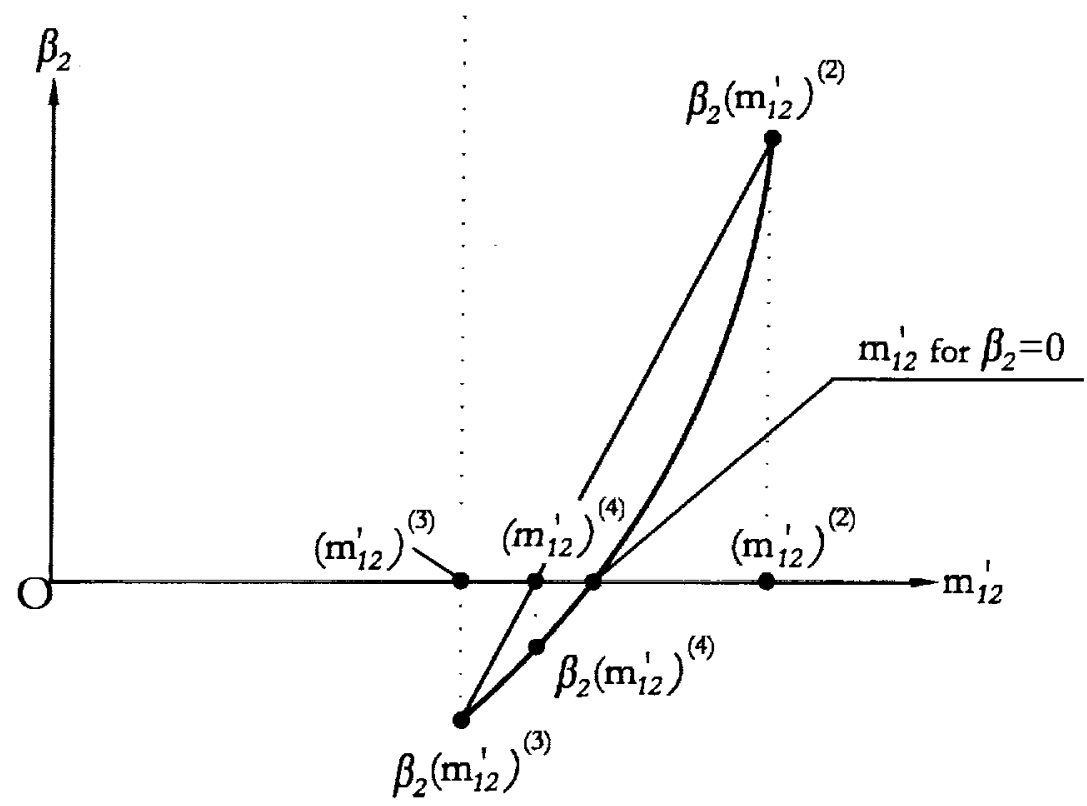

(b)

Figure 4.-Illustration of computations for determination of $\beta_{2}\left(m_{12}^{\prime}\right):$ (a) interpolation line for the third iteration; (b) interpolation line for the fourth iteration. 


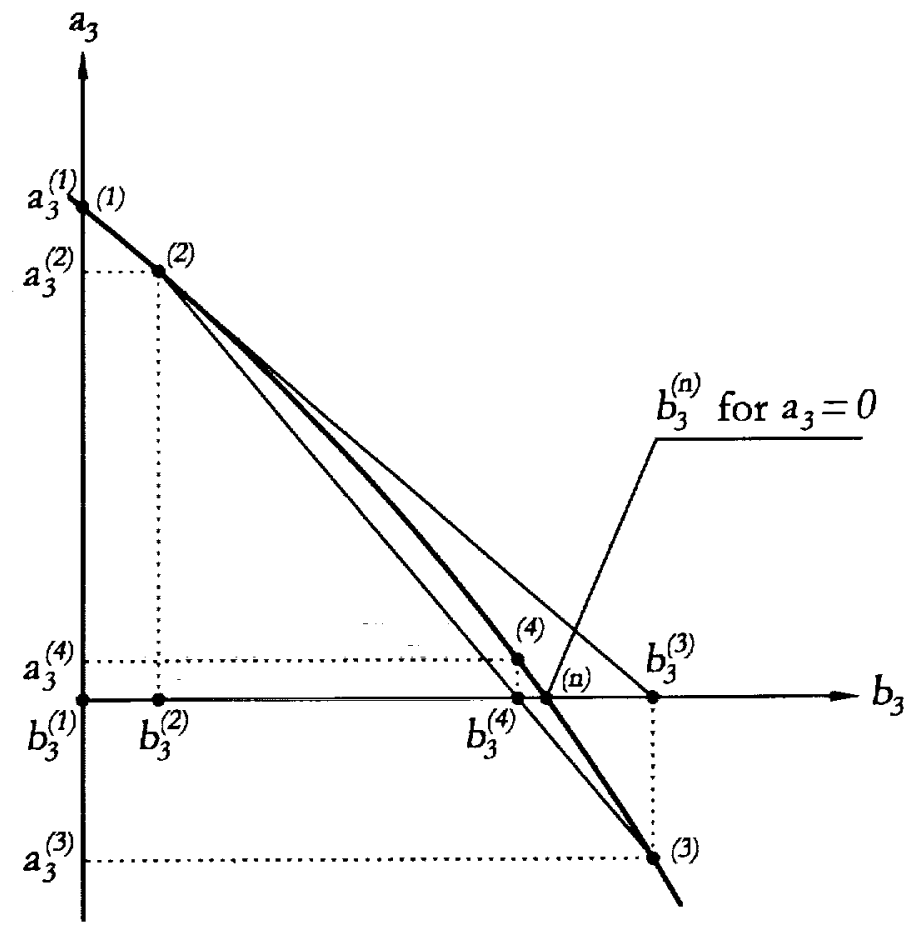

(a)

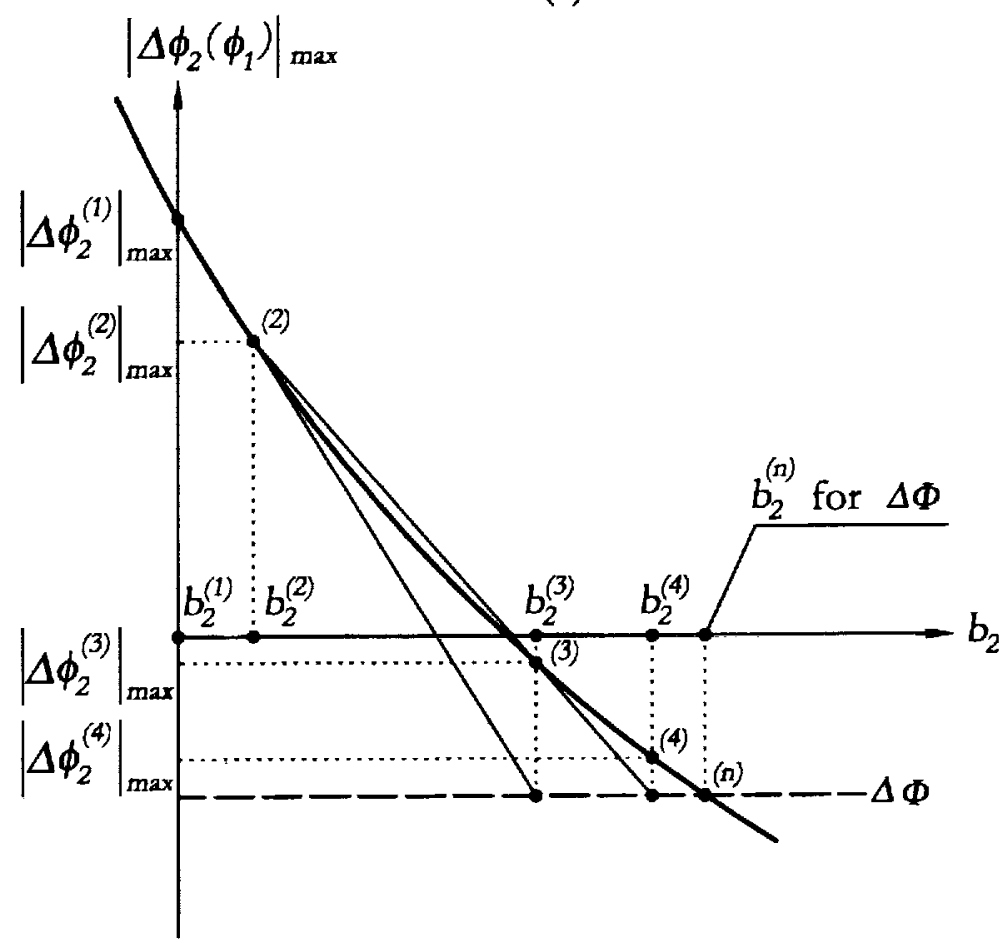

(b)

Figure 5.- (a) Illustration of variation of coefficient $b_{3}$ of modified roll; (b) illustration of variation of coefficient $b_{2}$ of modified roll. 


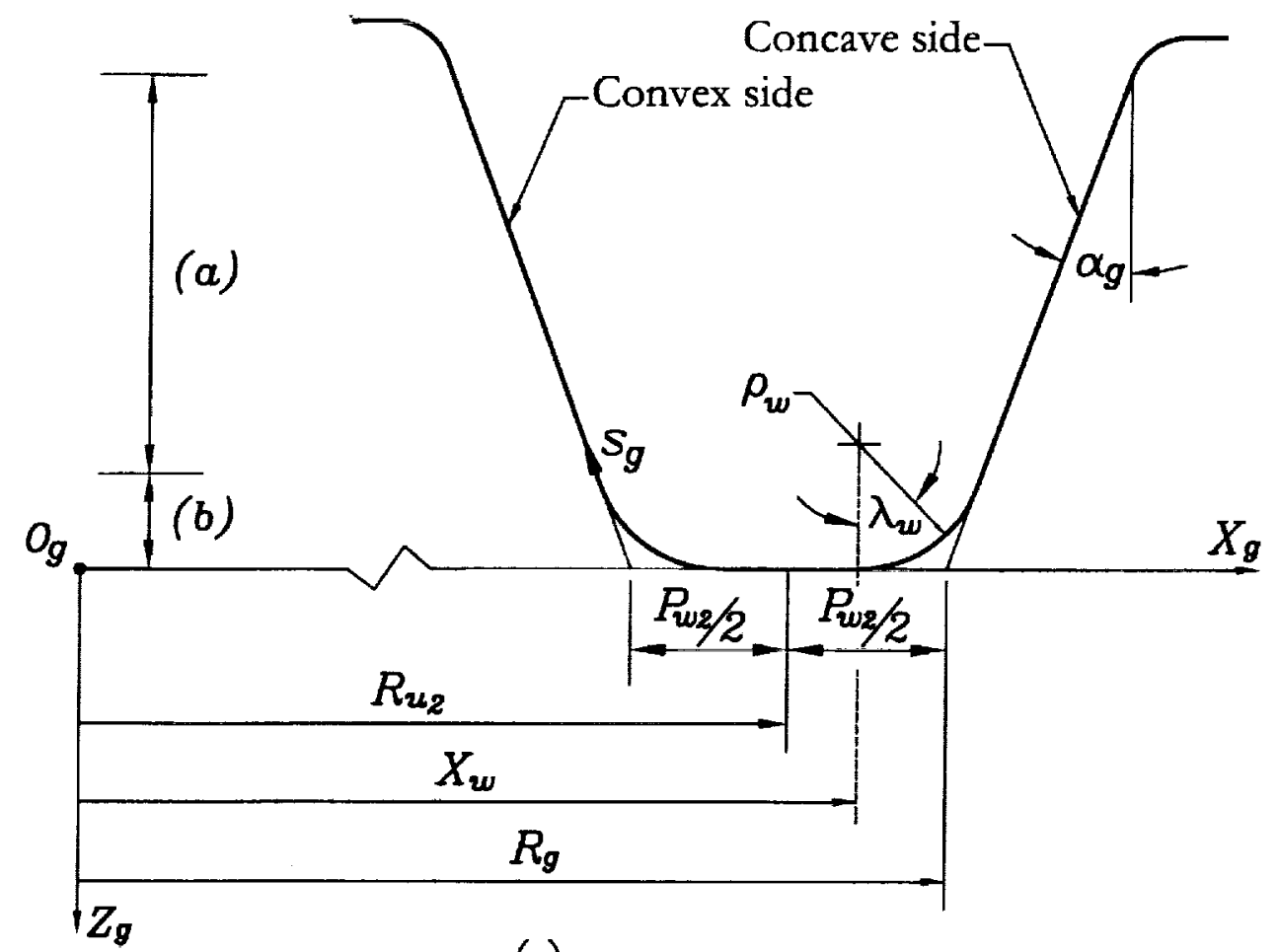

(a)

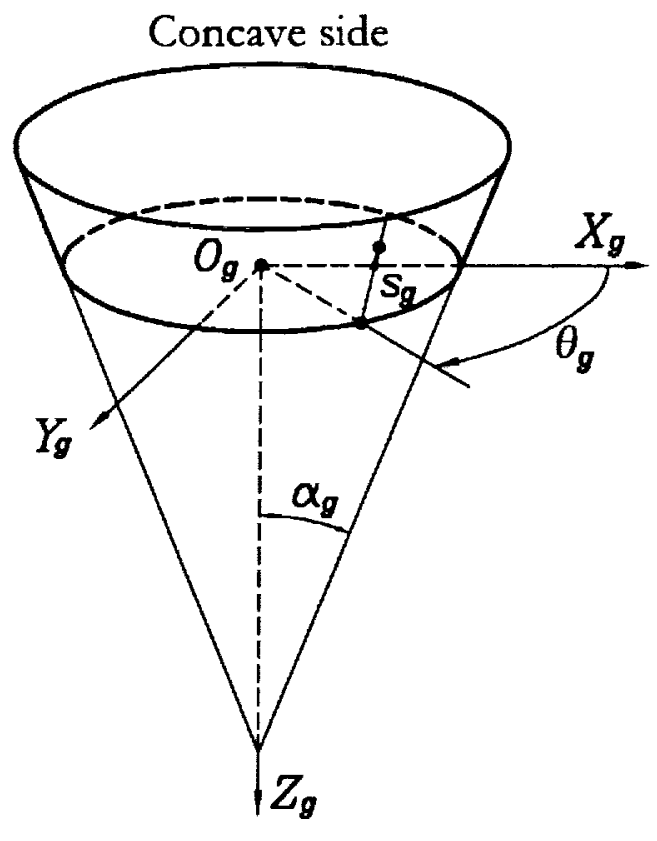

(b)

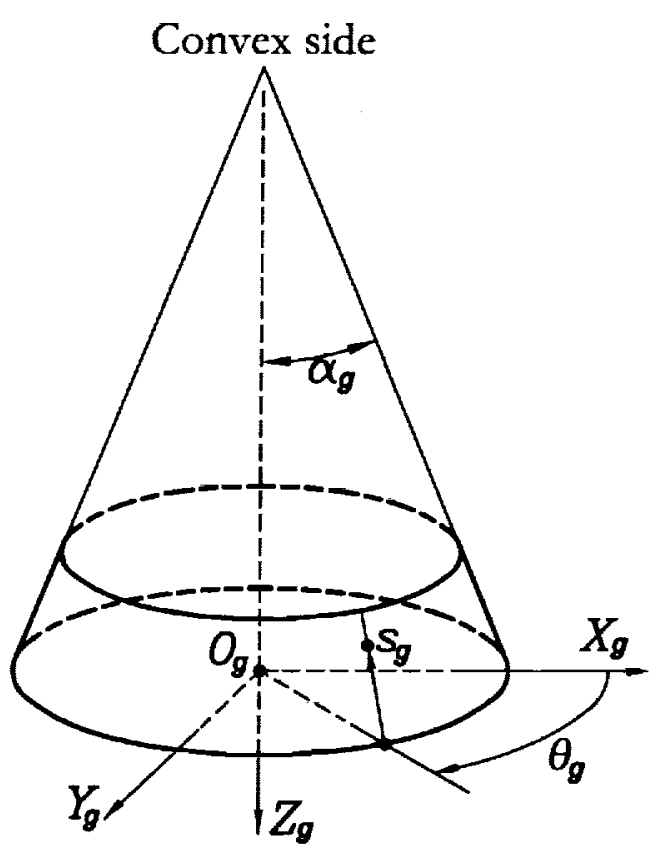

(c)

Figure 6.-Blade and generating cones for gear generating tool: (a) illustration of head-cutter blade; (b) and (c) generating tool cones for concave and convex sides. 

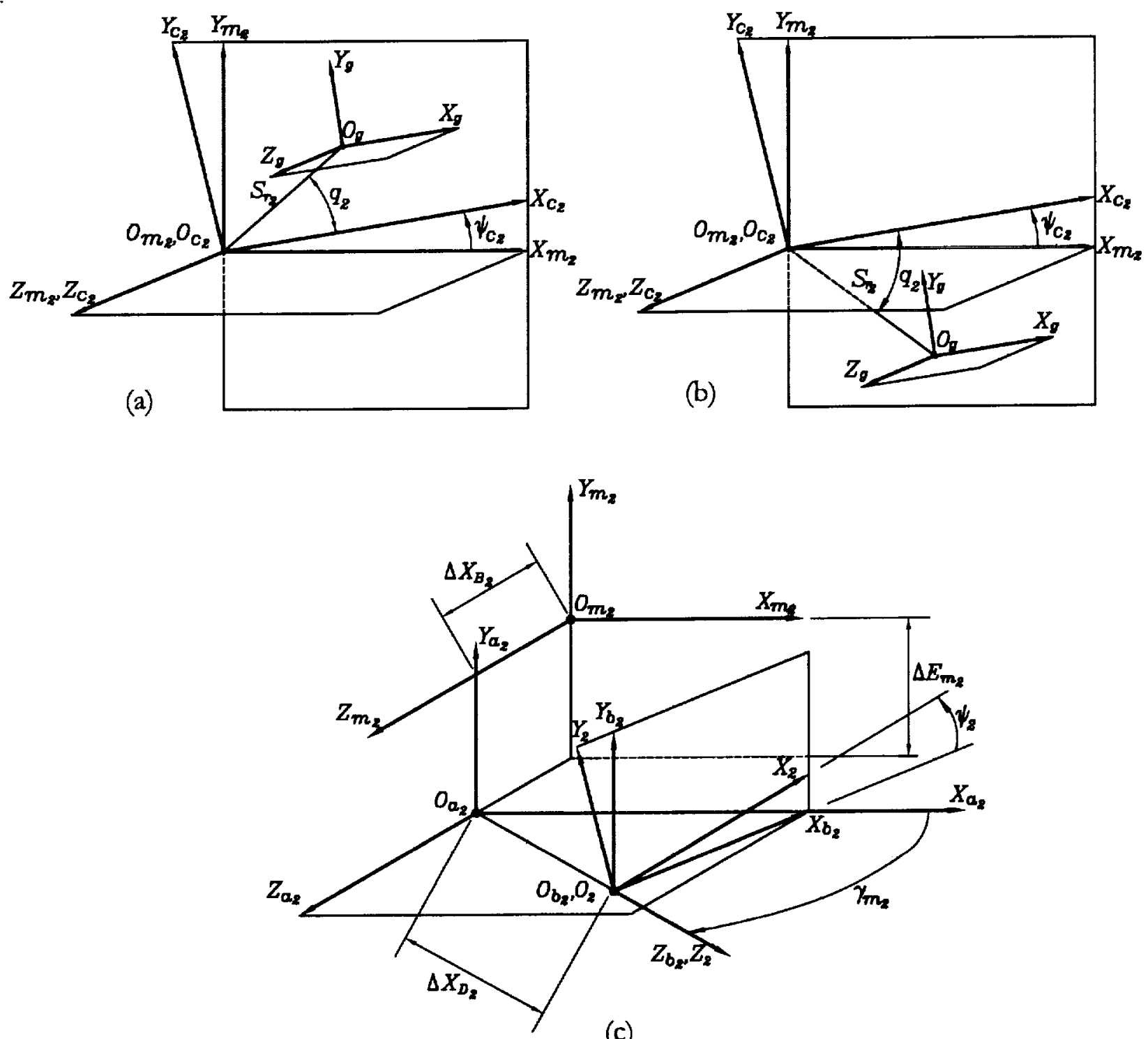

(c)

Figure 7.-Coordinate systems applied for gear generation: (a) and (b) illustration of tool installment for generation of right- and left-hand gears; (c) illustration of corrections of machine-tool settings. 


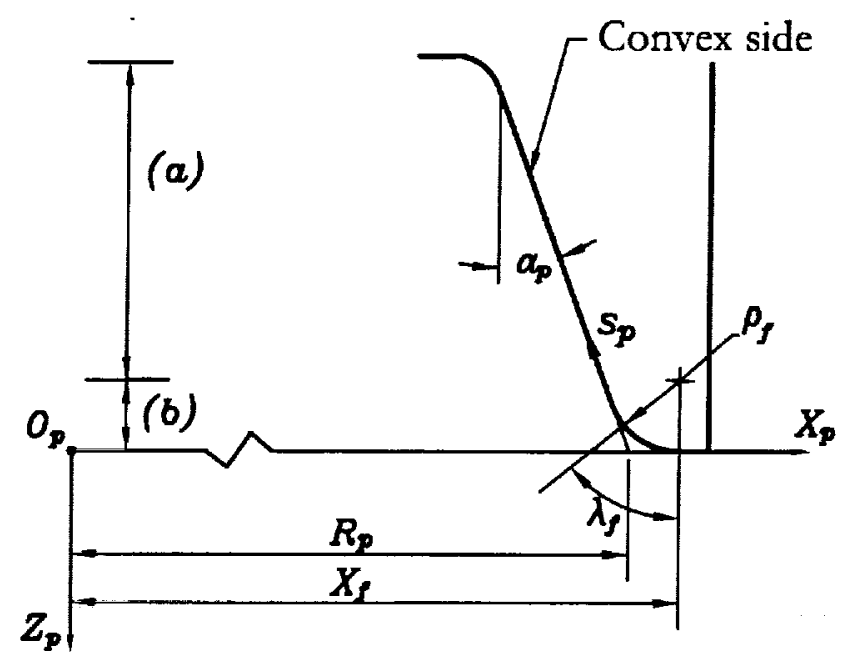

(a)

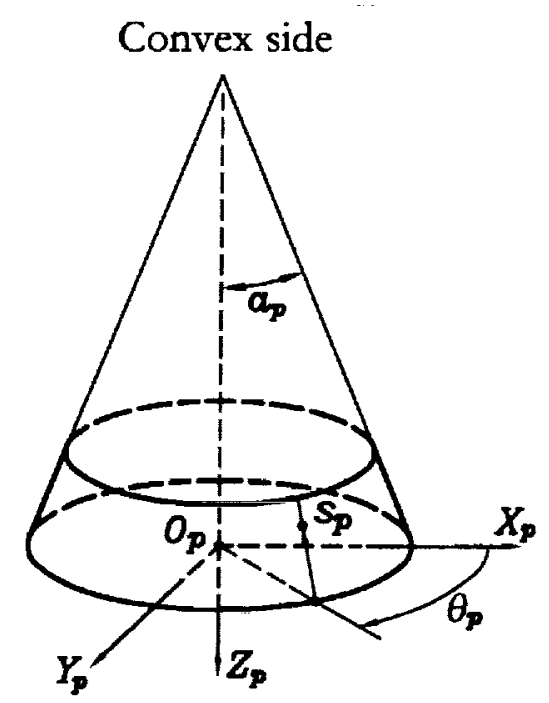

(b)

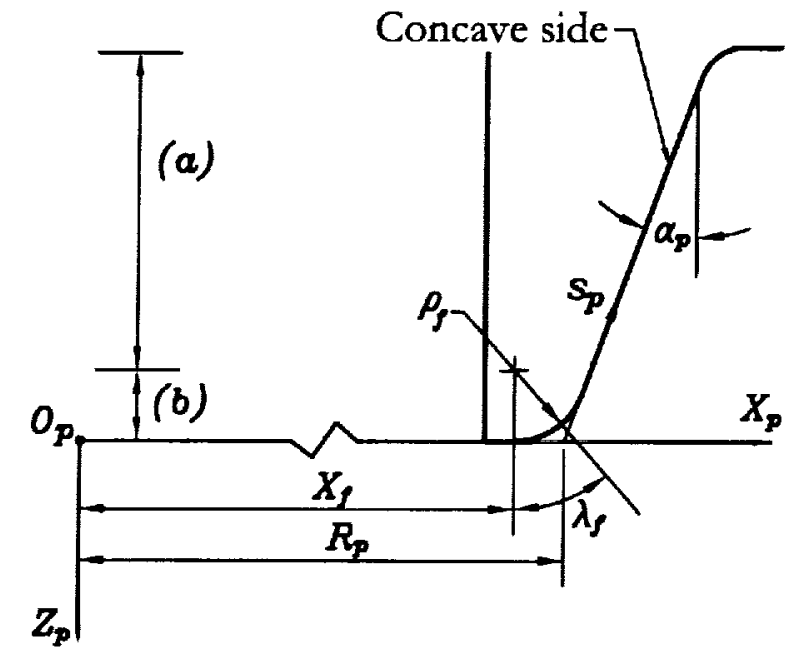

(c)

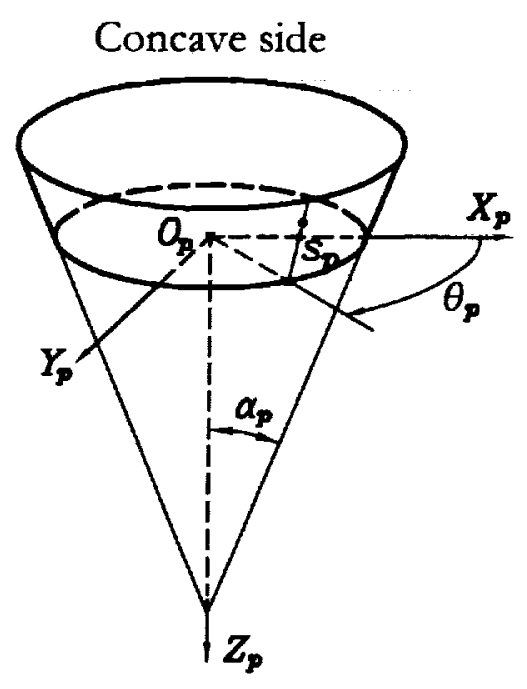

(d)

Figure 8.-Blades and generating cones for pinion generating tool with straight blades:

(a) convex side blade; (b) convex side generating cone; (c) concave side blade; (d) concave side generating cone. 

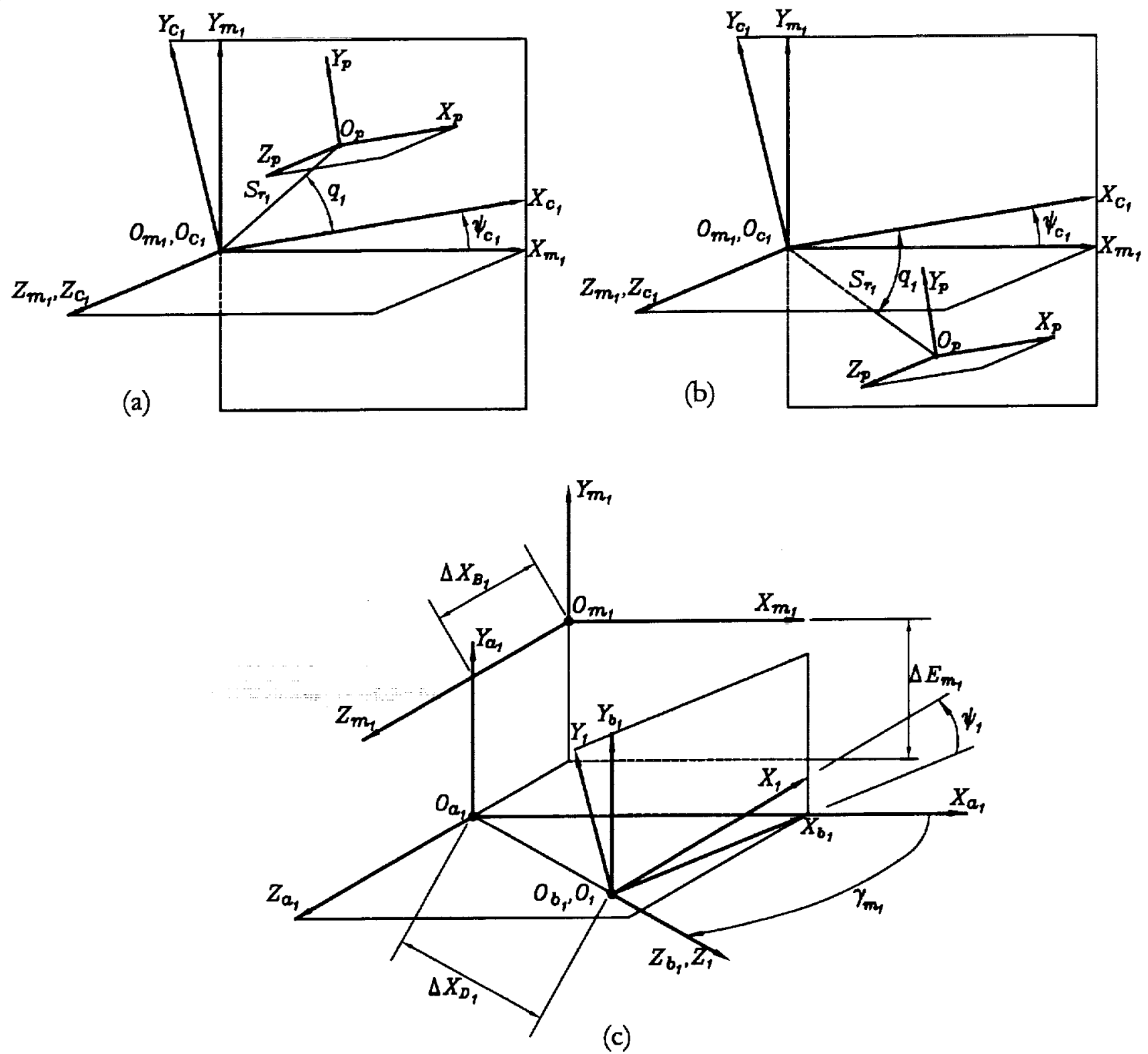

Figure 9.-Coordinate systems applied for the pinion generation: (a) and (b) illustration of tool installment for generation of right- and left-hand pinions; (c) illustration of corrections of machine-tool settings. 


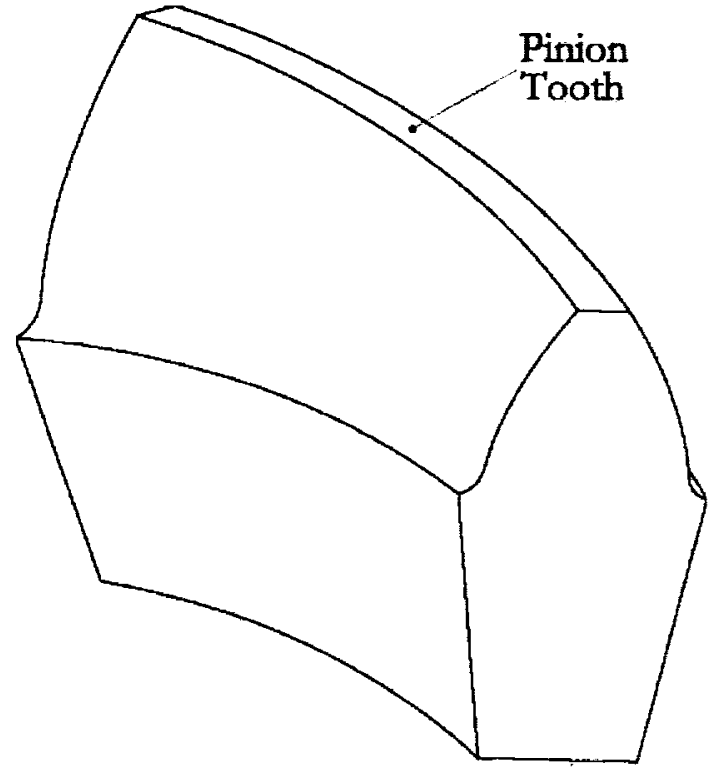

(a)

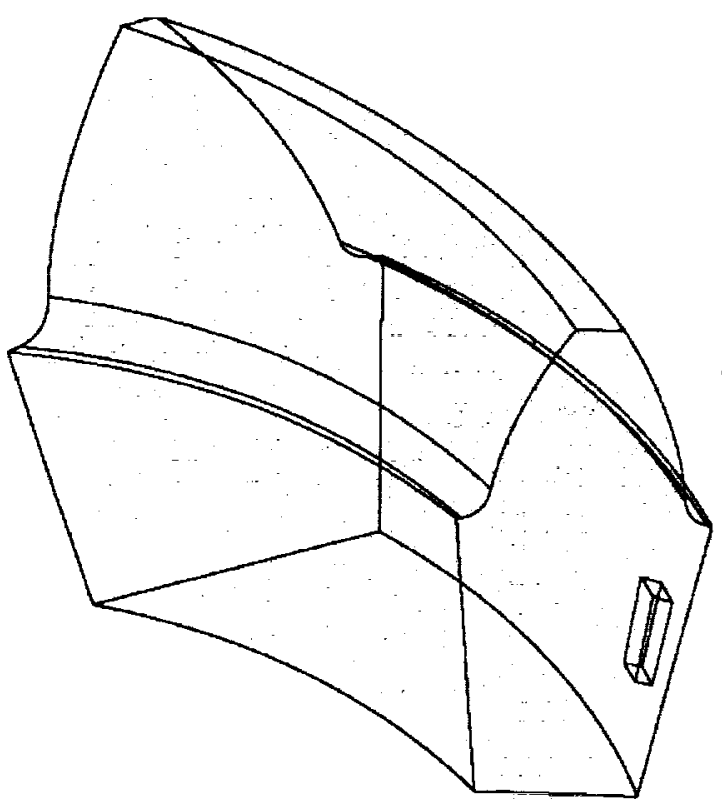

(c)

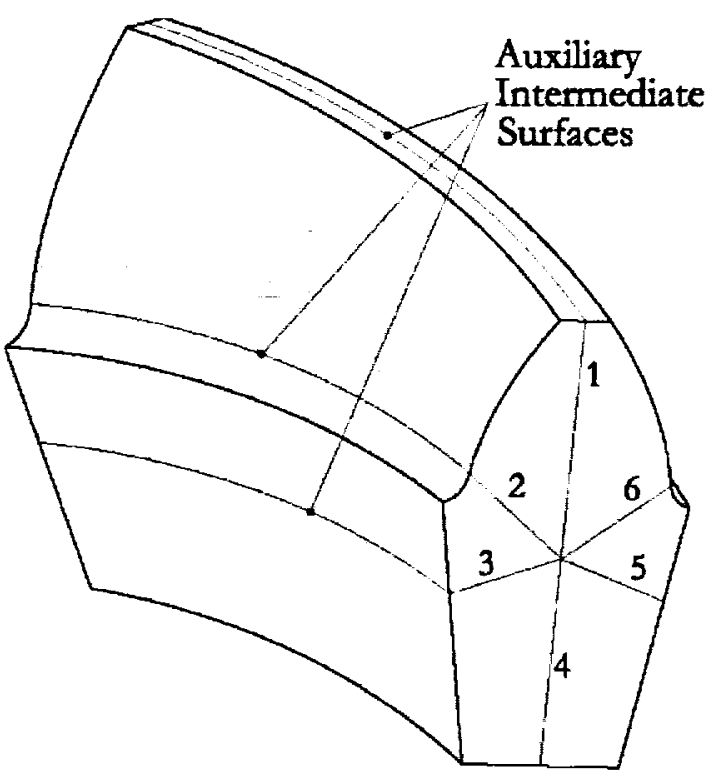

(b)

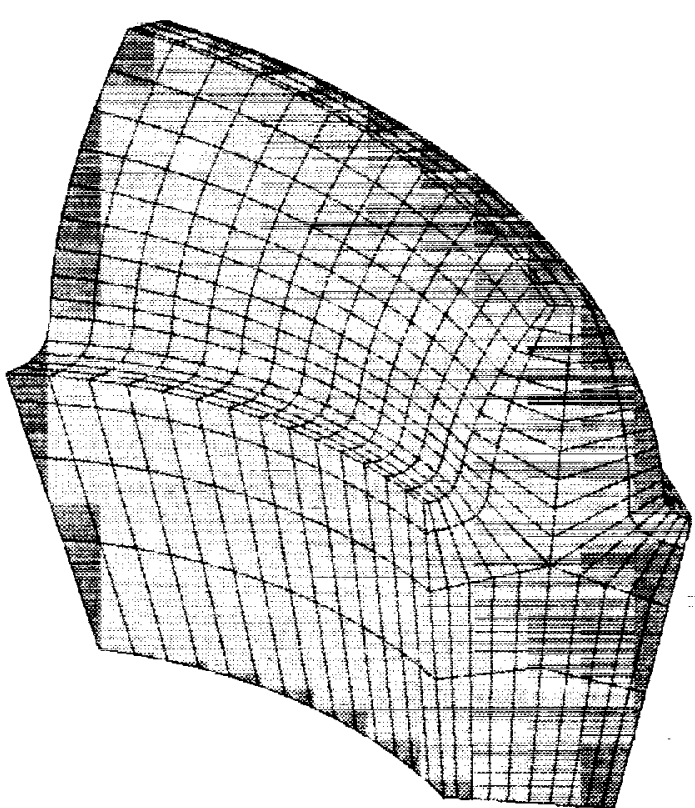

(d)

Figure 10.-Illustrations of (a) the volume of designed body, (b) auxiliary intermediate surfaces, (c) determination of nodes for the whole volume, and (d) discretization of the volume by finite elements. 


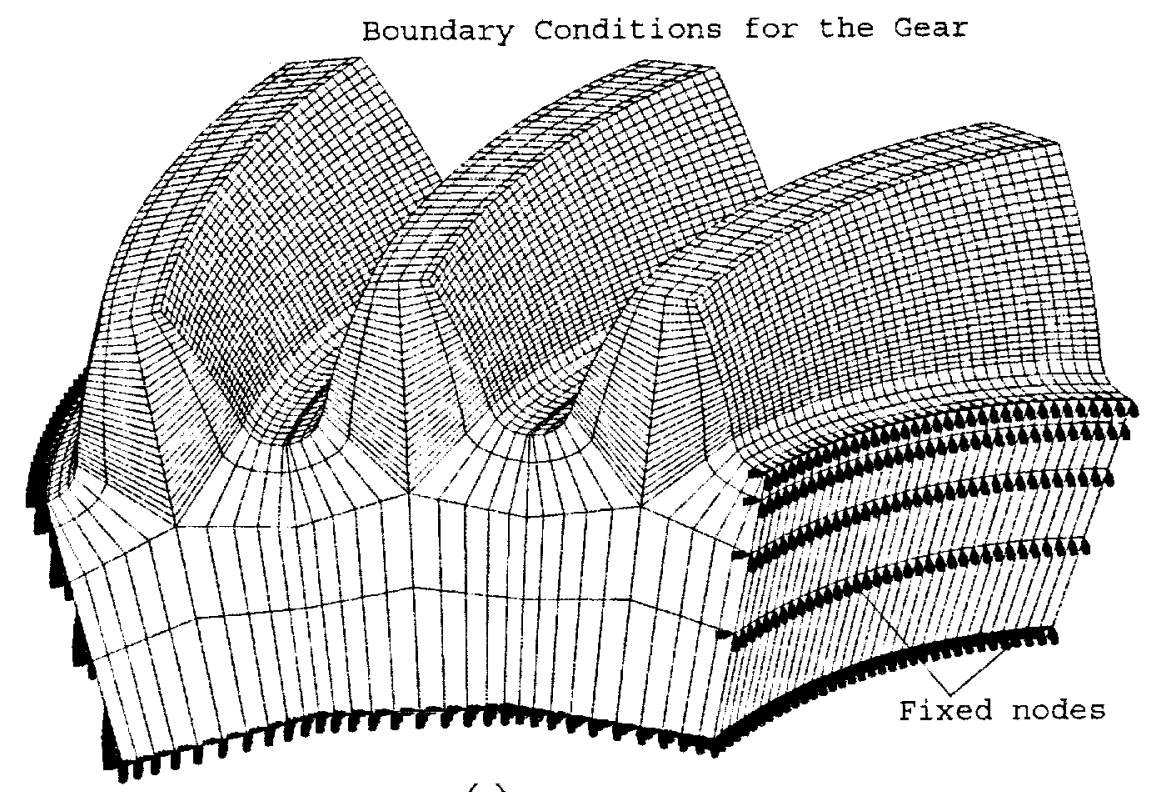

(a)

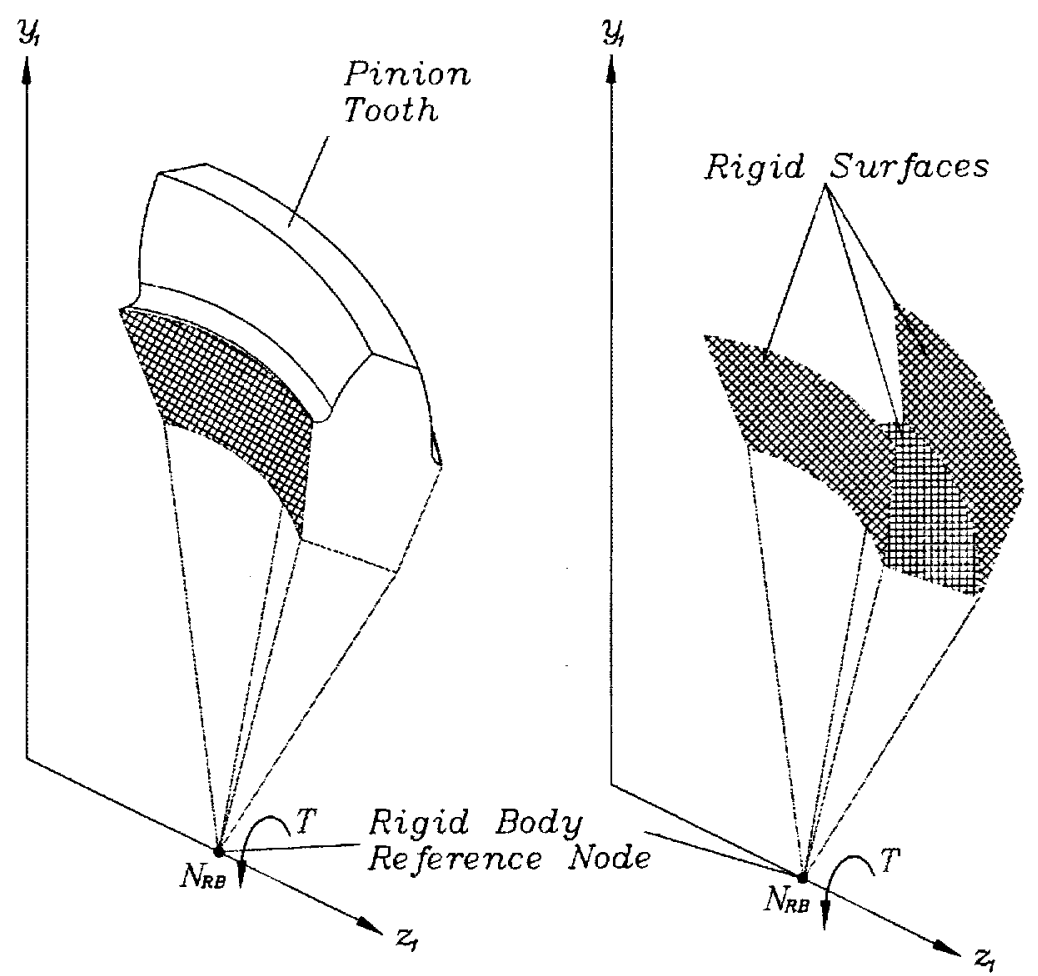

(b)

Figure 11.-(a) Boundary conditions for the gear and (b) schematic representation of boundary conditions and application of torque for the pinion. 


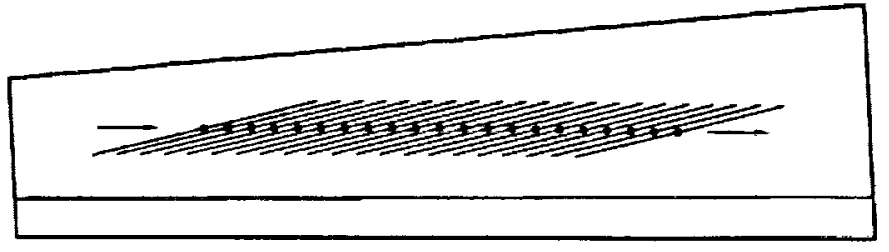

(a)

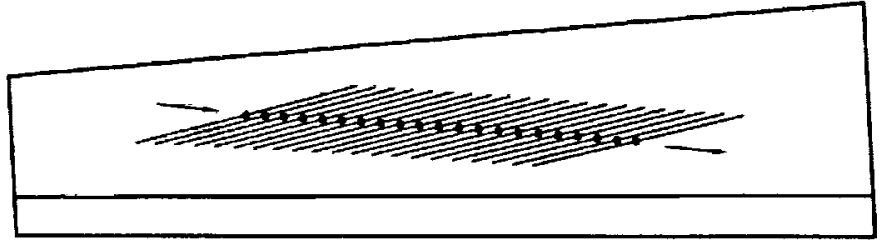

(b)

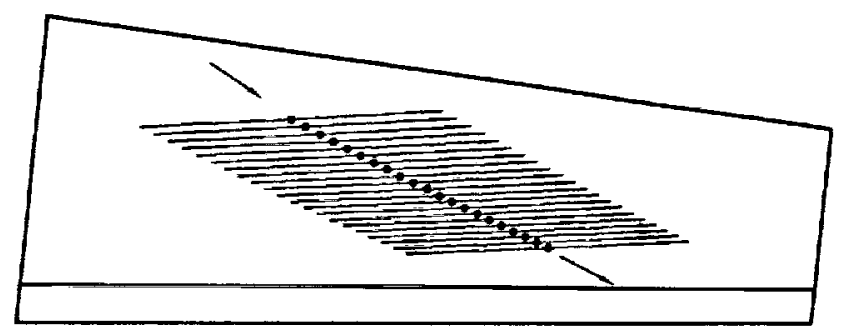

(c)

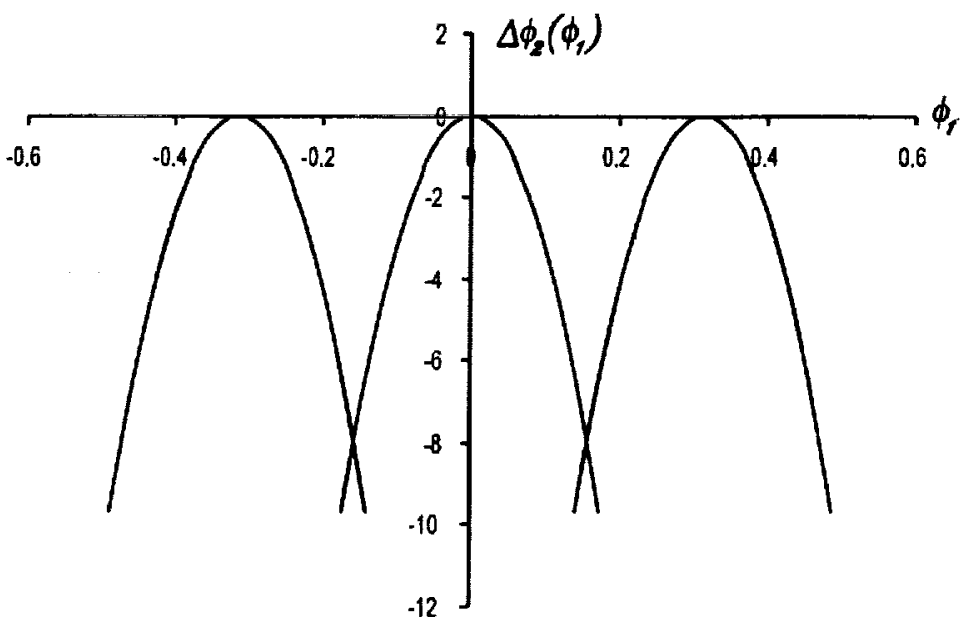

(d)

Figure 12.-Bearing contact represented on the gear surface and predesigned function of transmission errors: (a) longitudinally oriented bearing contact for gear drive of example 1; (b) adjusted bearing contact for gear drive of example 2; (c) adjusted bearing contact for gear drive of example 3 ;

(d) function of transmission errors for examples 1, 2, and 3. 


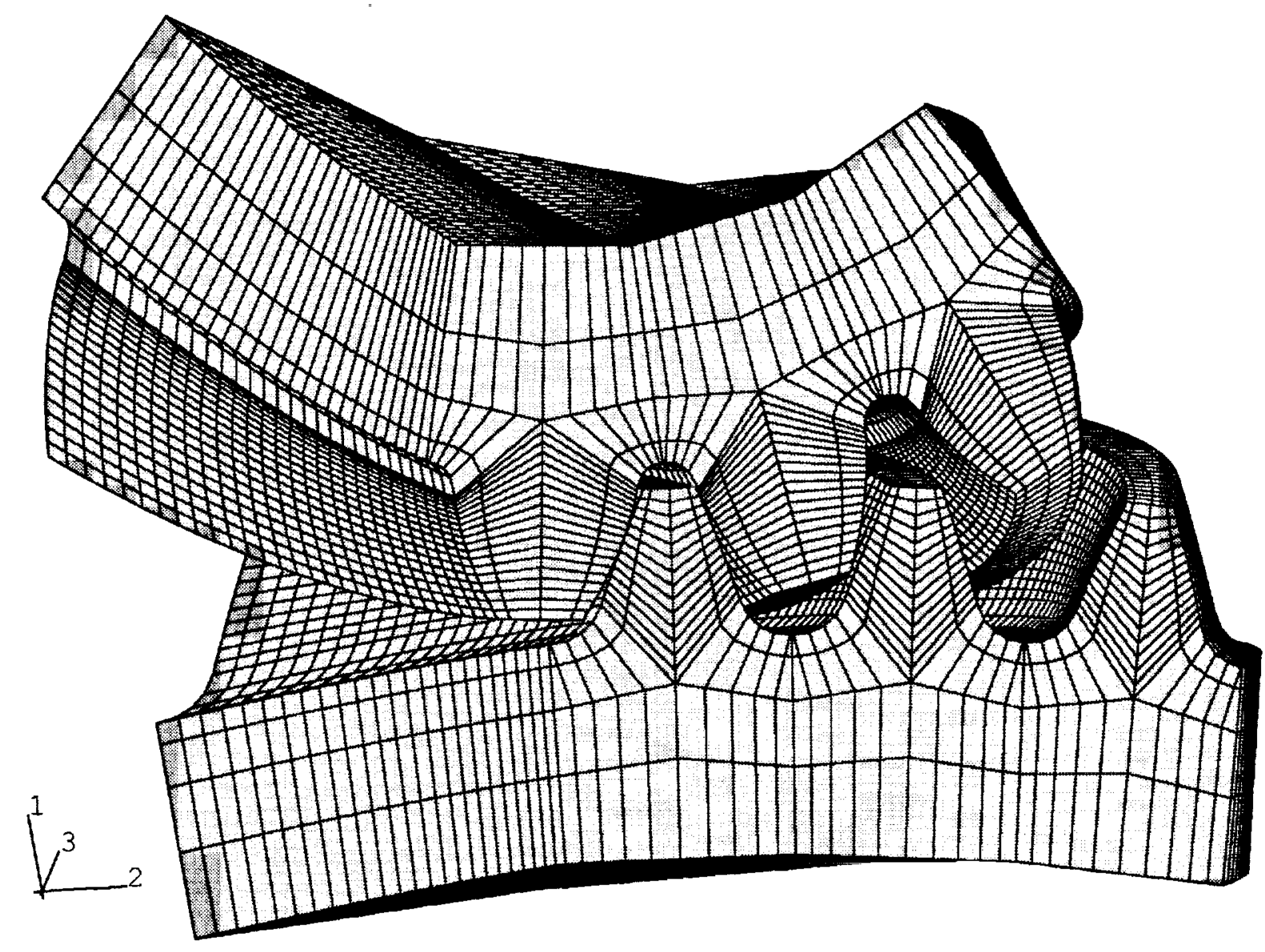

Figure 13.-Example 2: three-pair-of-teeth finite element mesh. 


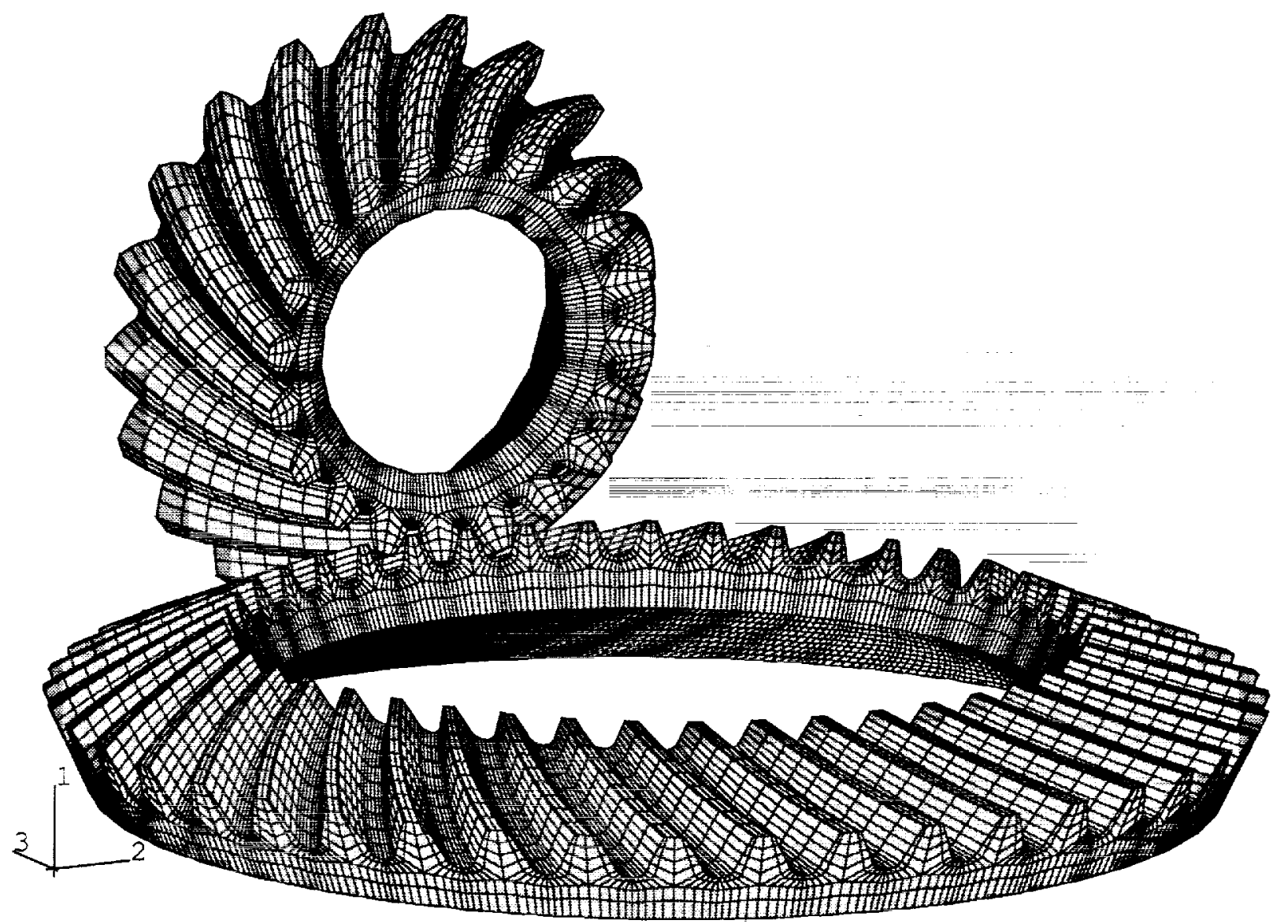

Figure 14.-Example 2: whole gear drive finite element mesh. 


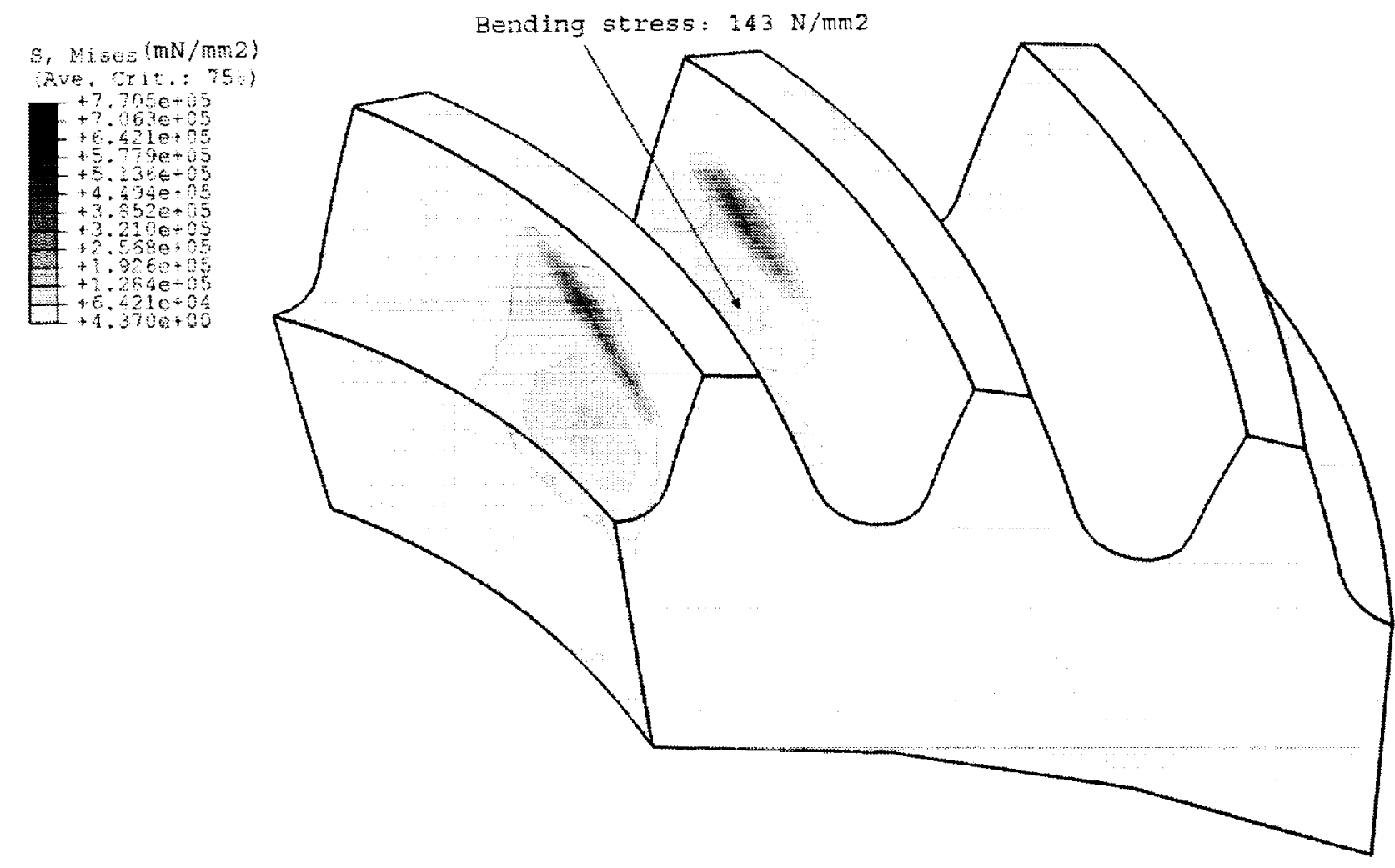

Figure 15.--Example 2: Bearing contact at heel contact point. 


\section{REPORT DOCUMENTATION PAGE}

Public reporting burden for this collection of information is estimated to average 1 hour per response, inciuding the time for revlewing instructions, searching existing data sources. gathering and maintaining the data needed, and completing and reviewing the collection of information. Send comments regarding this burden estimate or any other aspect of this Davis Highway, Suite 1204, Arlington, VA 22202-4302, and to the Office of Management and Budget, Paperwork Feduction Project (0704-0188), Washington, DC 20503.

\begin{tabular}{|c|c|c|}
\hline 1. AGENCY USE ONLY (Leave blank) & $\begin{array}{l}\text { 2. REPOAT DATE } \\
\text { January } 2002\end{array}$ & $\begin{array}{l}\text { 3. AEPOAT TYPE AND DATES COVERED } \\
\text { Final Contractor Report }\end{array}$ \\
\hline
\end{tabular}

Design and Stress Analysis of Low-Noise Adjusted Bearing Contact Spiral Bevel Gears

6. AUTHOR(S)

Faydor L. Litvin, Alfonso Fuentes, Baxter R. Mullins, and Ron Woods

7. PERFORMING ORGANIZATION NAME(S) AND ADDRESS(ES)

University of Illinois at Chicago

Gear Research Center

Department of Mechanical Engineering

Chicago, Illinois 60607-7022

9. SPONSORING/MONITORING AGENCY NAME(S) AND ADDRESS(ES)

National Aeronautics and Space Administration

Washington, DC 20546-0001

and

U.S. Army Research Laboratory

Adelphi, Maryland 20783-1145
WU-712-30-13-00

NAG3-2450

$1 \mathrm{~L} 162211 \mathrm{~A} 47 \mathrm{~A}$

11. SUPPLEMENTARY NOTES

Faydor L. Litvin and Alfonso Fuentes, University of Illinois at Chicago, Gear Research Center, Department of Mechanical Engineering, Chicago, Illinois 60607-7022; Baxter R. Mullins and Ron Woods, Bell Helicopter Textron, Inc., Fort Worth, Texas 76101. Project Manager, Robert F. Handschuh, U.S. Army Research Laboratory, NASA Glenn Research Center, 216-433-3969.

12a. DISTAIBUTION/AVAILABILITY STATEMENT 12b. DISTRIBUTION CODE

Unclassified - Unlimited

Subject Category: 37

Distribution: Nonstandard

Available electronically at http://gltrs.grc.nasa.gov/GLTRS

This publication is available from the NASA Center for AeroSpace Information, 301-621-0390.

13. ABSTRACT (Maximum 200 words)

An integrated computerized approach for design and stress analysis of low-noise spiral bevel gear drives with adjusted bearing contact has been developed. The computation procedure is an iterative process, requiring four separate steps that provide: (a) a parabolic function of transmission errors that is able to reduce the effect of errors of alignment, and (b) reduction of the shift of bearing contact caused by misalignment. Application of finite element analysis permits the contact and bending stresses to be determined and investigate the formation of the bearing contact. The design of finite element models and boundary conditions is automated and does not require an intermediate CAD computer program. A commercially available finite element analysis computer program with contact capability was used to conduct the stress analysis. The theory developed is illustrated with numerical examples.

\section{SUBJECT TERMS}

Gears; Drive systems

15. NUMBER OF PAGES

35

16. PRICE CODE

17. SECURITY CLASSIFICATION
OF REPORT
Unclassified

Unclassified

18. SECUAITY CLASSIFICATION
OF THIS PAGE
Unclassified

Unclassified
19. SECURITY CLASSIFICATION OF ABSTRACT

Unclassified 